\title{
Managing care pathways for patients with complex care needs
}

\section{Magdalena Smeds}

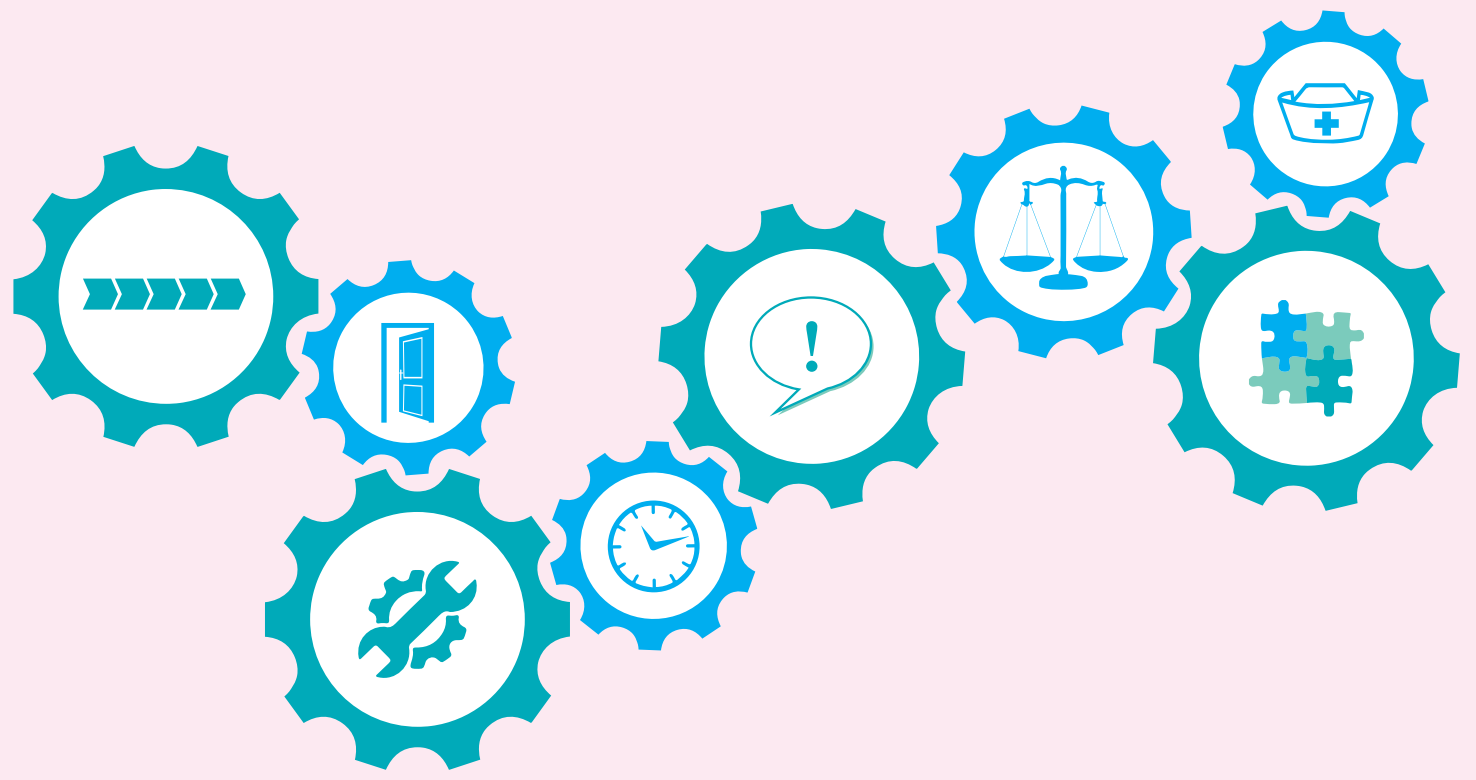


Linköping studies in Science and Technology

Licentiate Thesis No. 1839

\title{
Managing care pathways for patients with complex care needs
}

\author{
Magdalena Smeds
}

2019

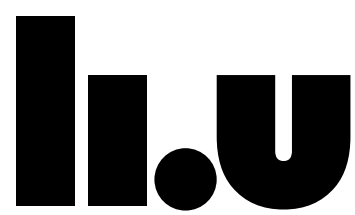

LINKÖPING UNIVERSITY

Logistics and Quality Management

Department of Management and Engineering

Linköping University, SE-581 83 Linköping, Sweden 
(c) Magdalena Smeds

Linköping studies in Science and Technology, Licentiate Thesis No. 1839

ISBN: 978-91-7685-069-5

ISSN: 0280-7971

Cover: Marcus Lundberg

Printed by LiU-Tryck, Linköping 2019

The published article has been reprinted with the permission of the copyright holder.

Distributed by:

Linköping University

Department of Management and Engineering

SE-581 83 Linköping, Sweden

Tel: +461328100 


\section{Abstract}

One of the central challenges for the healthcare system today is how to manage care for patients with complex needs. This patient group is not well-defined but covers patients with serious diseases and comorbidities, or with a limited ability to perform basic daily functions due to physical, mental or psychosocial challenges. This group has a high service and resource utilisation resulting in high costs for the healthcare system and, typically, poor health outcomes. To improve care for these patients, it is necessary to implement strategies to manage the differentiated care needs, the additional support needs, the uncertainty in care delivery, and the coordination needs of the involved providers and the patient.

Care pathways are increasingly used internationally to make care more patient-centred and to structure and design care processes for individual patient groups. Important elements in care pathways include structuring care activities, by defining their content and sequence; coordinating between providers and professionals; and involving patients in their care process. In this thesis, care pathways are proposed as the overall strategy for managing care for patients with complex care needs.

The purpose of this thesis is thus to contribute with knowledge on how care pathways can be managed for patients with complex care needs. This is achieved by analysing how the practices coordination, standardisation, customisation and personalisation can support management of care pathways and by discussing how these practices influence quality of care. The quality of care dimensions discussed are accessible, timely, equitable, and patient-centred care.

The empirical context in this thesis is the Standardised Cancer Care Pathways (CCPs) which were implemented in Sweden from 2015 to 2018. CCPs is the umbrella term for the national initiative to shorten waiting times, decrease regional differences and reduce fragmentation in care processes. CCPs include elements such as diagnosis-specific pathways and guidelines, introduction of CPP coordinators, and mandatory reporting of waiting times. Focus has been on implementing care pathways for 31 cancer diagnoses in all Swedish healthcare regions.

Both qualitative and quantitative research methods have been used. A case study was conducted to examine standardised and customised care pathways, and coordination and multidisciplinary work in care pathways. A document study of regional reports on CCPs was analysed to study effects of care pathways on accessibility, timeliness and equitability. Finally, a national survey was conducted to deepen the understanding of the role of coordination, as performed by coordinators, in care pathways.

This thesis argues that standardised and customised care pathways should be combined to manage care for patients with complex care needs. The customised pathway in particular benefits patients with serious unspecific symptoms, unknown primary tumour or more complex care needs, while patients with care needs that can be treated independently of the main diagnosis benefit from following a standardised care pathway.

Coordinators are an important means to manage coordination, customisation and personalisation in the care pathway. The coordinators' role is twofold: the first role is to manage care pathways by customising the care pathway and coordinating involved providers; the second role is to support and guide patients through the care pathway. This can be achieved by adapting interpersonal communication with patients through personalisation.

This thesis further argues that care pathways have most potential to positively influence accessibility, timeliness, equitability, and patient-centredness. Accessibility has been positively influenced, especially for patients with ambiguous symptoms where symptoms indicating cancer have improved their chances of accessing cancer diagnostics. A negative aspect of prioritising patients who follow CCPs has been the potentially longer waiting times for other patient groups in equal need of urgent care. Notwithstanding, prioritised access to care is perceived to positively influence timeliness for patients following CCPs. Care pathways are perceived to have positively influenced patient-centredness by shifting the focus from what to deliver to how to deliver it. 


\section{Acknowledgements}

I would like to start by thanking my supervisors Bonnie Poksinska and Mattias Elg.

Bonnie, I cannot thank you enough for giving me the opportunity to become a PhD student. When I dared to express an interest in research, I never imagined that my dream would come true. Especially not within a few months! It started with the Master's thesis and, now, here I am. I have learnt so much during these years and I have really appreciated all the time we spent together in our projects. You are an incredibly wise person and I have learned so much from you. I cannot express how incredibly grateful I am for this experience. I wish you good luck in your new adventure and I really hope we get the chance to work together again soon!

Mattias, I owe you a big thank you for the time you spent listening to my rambling thoughts and the questions you asked that made everything fall into place. When I have felt lost in my own thoughts, you have been there to help me put words on things I did not even know that I knew. I am also very grateful that I get the chance to continue this journey. Both research and teaching are very close to my heart and I am so grateful that I can continue to develop myself as a researcher and teacher(!), and I look forward to taking on new challenges!

I would also like to thank Jon Engström who was the opponent at my final seminar. You came with the right feedback at the right time. You gave me the advice and remarks I needed to move on. Thank you so much!

I would also like to thank all those whom I have had the great pleasure of getting to know during this journey through conferences, network meetings, projects and so on. Thank you Marie and Per-Anders at Region Östergötland for helping me see another side of CCPs. Thanks to Christina and Ingrid from the National Board of Health and Welfare and Srinivas from the Regional Cancer Centre South-East for exciting collaborations. I would also like to thank the respondents in the various projects. Without you, this would not have been possible!

LQ, what can I say? Working hard or hardly working, is an expression that fits well to our work days. We all work very hard - but spending time at the office does not really feel like work when you are around! You all inspire me to try to be the best co-worker, teacher, and researcher I can be! Thank you to Kristina Dahlberg for helping me with preparing and organising my licentiate thesis defence. Special thanks to all of you, * especially Henrik, Niklas, Linnea, Promporn, Björn, Jason, and Malin *, who have taken the time to read and give feedback on my thesis.

Finally, I would like to thank all of you who have been there for me during the years. Peter, I hope we will continue to disagree on things our whole lives - I would not have been the person I am today without our discussions. Mum and sis, you will always be my biggest inspirations: for your tireless striving for what you believe in and for going your own way. Your accomplishments never cease to amaze me! Hillevi, Johanna and Sabina, you have always supported me to an extent that I will never be able to return - but I will spend my life trying. Lisen my adorable cat, I hope you will continue to keep me company on the couch when I am working late for many more years to come. Endless LOVE, HUGS, and KISSES to all my family and friends for supporting, challenging, and encouraging me all day, every day. Calleth You, Cometh I 


\section{List of appended papers and the author's contribution}

I. Smeds, M. (2018), The management of cancer care pathways in a coordination centre. Presented at the QMOD Conference, August 2018 in Cardiff, Wales, United Kingdom.

The paper is partly based on the author's Master's thesis on the topic standardised cancer care pathways conducted in 2016. The main part of the data came from the Master's thesis and the remainder from the literature review on care pathways conducted by the author for this paper. The author was responsible for the data collection, data analysis, and design and writing of the paper.

II. Smeds, M., Poksinska, B., Carlsson, C., and Schmidt, I., (2018), Care coordinators as a means to improve continuity and quality of patient care. First version presented at the EUROMA Conference June 2018 in Budapest, Hungary. Submitted to journal, 2019-02-22.

The study presented in this paper was conducted on behalf of the National Board of Health and Welfare. The National Board of Health and Welfare was responsible for the study idea, and for distributing and collecting survey responses. The first and second author developed a draft of survey questions and later made the first preliminary analysis of the responses. These were repeatedly discussed by all authors whereupon changes were made. The second author had main responsibility for conducting the quantitative data analysis and the first author had main responsibility for the qualitative data analysis. However, both were involved in the whole analysis process. The first author was responsible for writing the draft of the papers for the conference and the submitted version, which were reworked jointly by all authors.

III. Smeds, M. and Poksinska, B. (2018), The effects of cancer care pathways on waiting times. Published in the International Journal of Quality and Service Science (IJQSS), https://doi.org/10.1108/IJQSS-04-2018-0041

The idea for the paper came from the second author but both authors developed the design of the study. The first author was responsible for the document study and the primary analysis of the data subsequent to which both authors discussed the results. The first author was responsible for writing the introduction, research findings and parts of the analysis in the paper, and has in addition been involved in all parts of the paper. 


\section{Table of Contents}

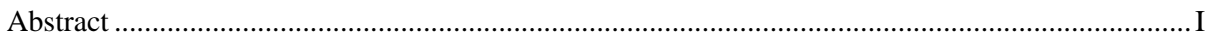

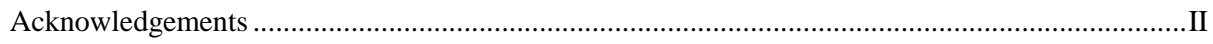

List of appended papers and the author's contribution ........................................................... III

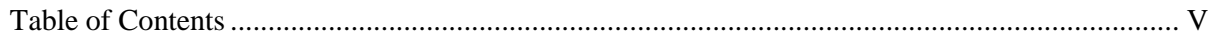

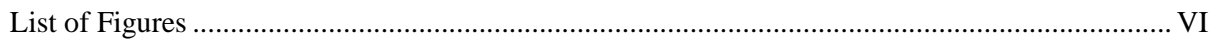

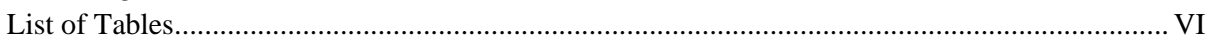

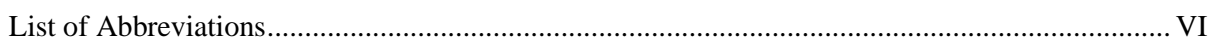

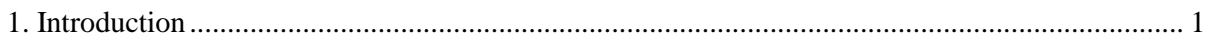

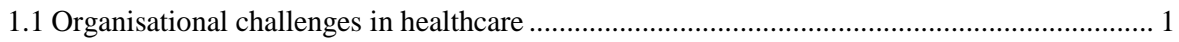

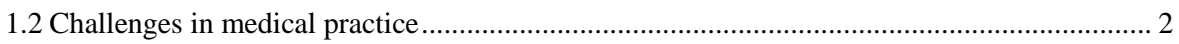

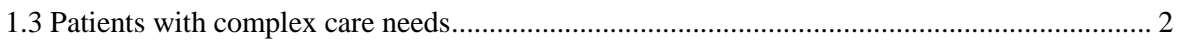

1.4 Managing care for patients with complex care needs ....................................................... 3

1.4.1 Managing variation and uncertainty ......................................................................... 3

1.4.2 Managing interdependencies between people and activities ....................................... 5

1.4.3 Managing provider-patient communication ........................................................ 5

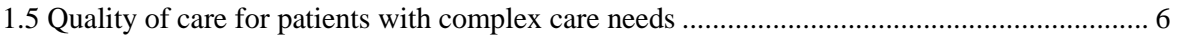

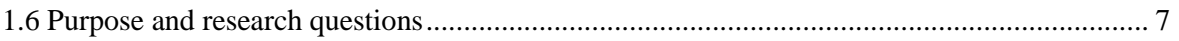

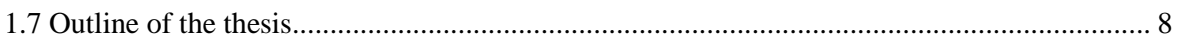

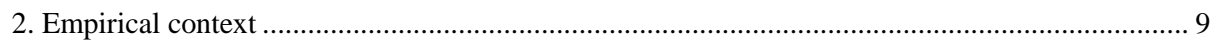

2.1 The Swedish healthcare system .................................................................................. 9

2.2 Swedish cancer care ............................................................................................... 9

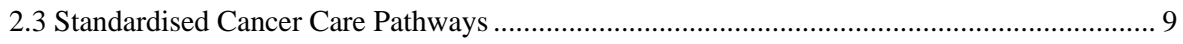

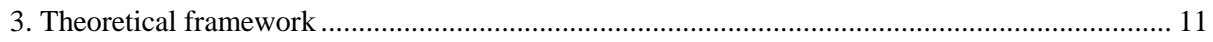

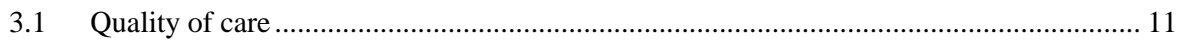

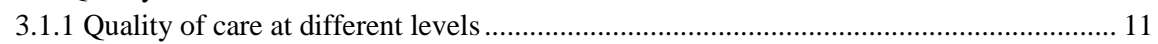

3.1.2 Assessing quality of care through structure, process and outcome ............................. 11

3.1.3 Quality of Care Framework................................................................................... 12

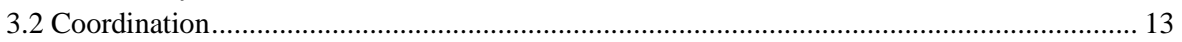

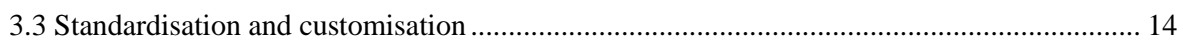

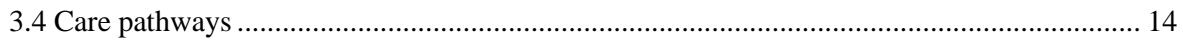

3.4.1 Managing care pathways .................................................................................... 15

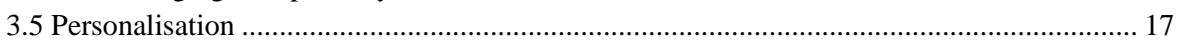

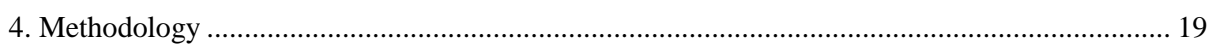

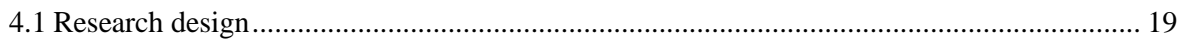

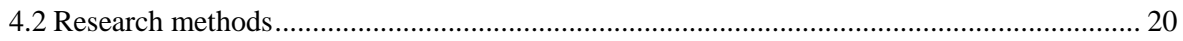

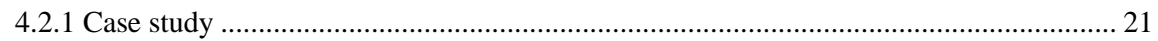

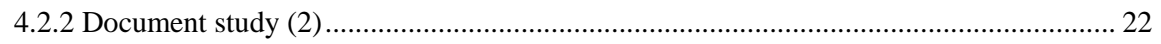

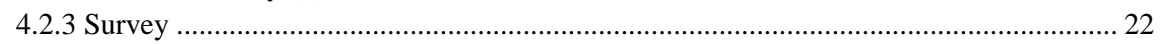

4.2.4 Literature review and formation of theoretical framework .......................................... 23

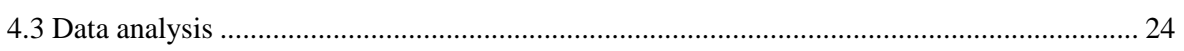

4.4 Methodological considerations .......................................................................................... 24

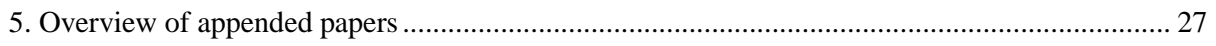

5.1 Paper I: The management of cancer care pathways in a coordination centre ....................... 27

5.2 Paper II: Care coordinators as a means to improve continuity and quality of patient care .... 27 
5.3 Paper III: The effects of cancer care pathways on waiting times ........................................ 28

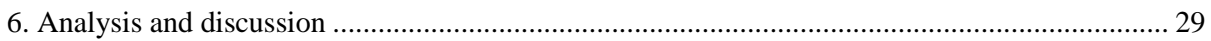

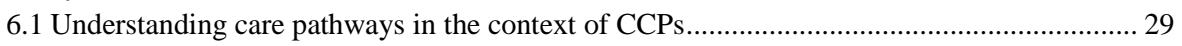

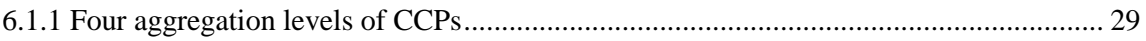

6.1.2 Care pathways and coordinators as coordination mechanisms ……………................. 30

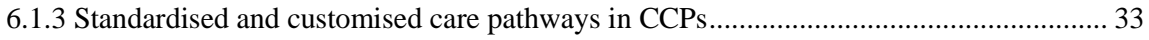

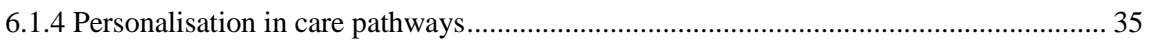

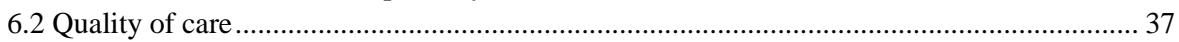

6.2.1 Access to care

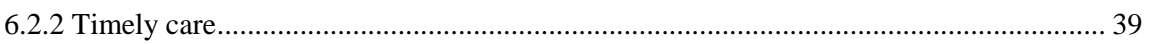

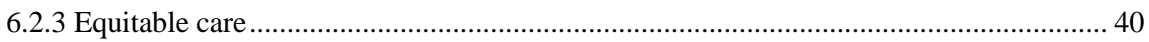

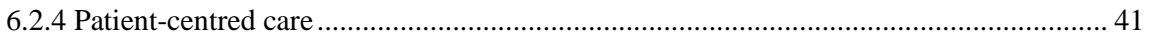

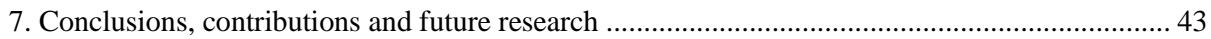

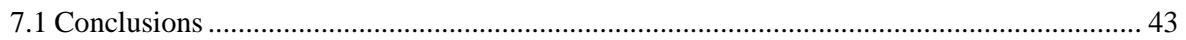

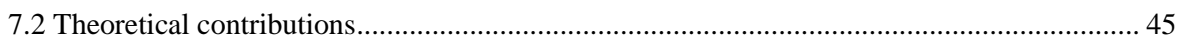

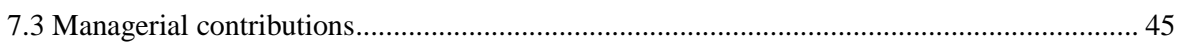

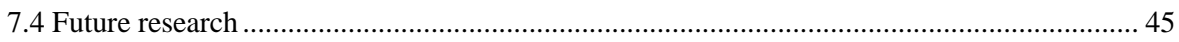

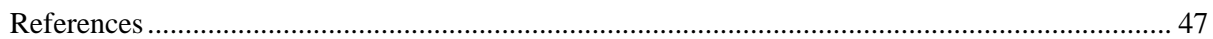

\section{List of Figures}

Figure 1: The Quality of Care Framework used in this thesis (based on Donabedian (1966) and

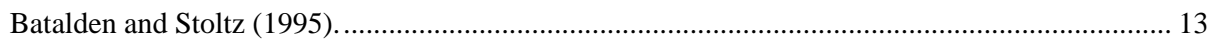

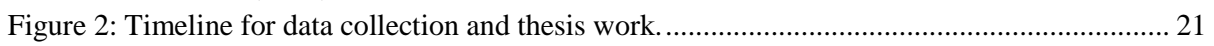

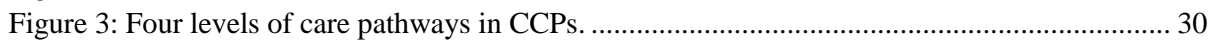

Figure 4: Application of the empirical material to the Quality of Care Framework........................ 37

\section{List of Tables}

Table I: Summary of characteristics of the standardised care pathway ............................................. 16

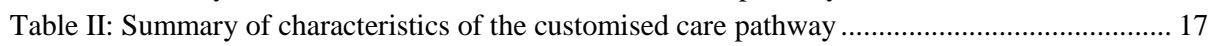

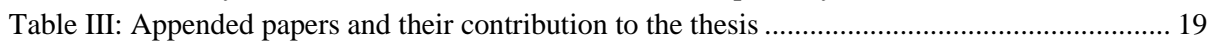

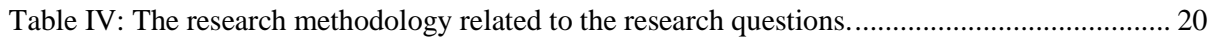

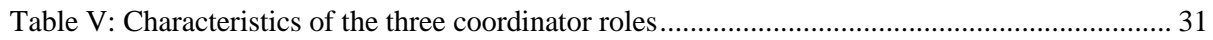

Table VI: Characteristics for care pathways to manage care for patients with complex care needs.34

\section{List of Abbreviations}

CCP - Standardised cancer care pathways (In Swedish: Standardiserade Vårdförlopp, SVF)

CUP - Cancer of unknown primary tumour

SUS - Serious unspecific symptoms 


\section{Introduction}

This chapter introduces the thesis and presents organisational and medical practice challenges; patients with complex care needs; previous research on managing care for patients with complex care needs; and quality of care for patients with complex care needs. The last part of the chapter presents purpose and research questions as well as an outline of the thesis.

The aim of the healthcare system is to ensure good health and care on equal terms for the entire population (Government Offices Of Sweden, 1982). However, current developments such as growing and aging populations (Institute of Medicine, 2001), changed demography (Nolte and McKee, 2008), and advances in medical knowledge and technology (Anell, 2005) are perceived as potential barriers to achieving this aim. The changed population demographics has resulted in a higher incidence of patients with severe and chronic conditions as well as comorbidities. This has placed is an increased burden on care for patients with complex care needs (Bodenheimer and Berry-Millett, 2009) sometimes called "super-utilizers" due to their multiple physical, mental or psychosocial needs (Thomas-Henkel et al., 2015 p.3).

A central challenge in the healthcare system today is how to manage care in order to achieve this goal, presented above, in this new situation (Thomas-Henkel et al., 2015, Palmer et al., 2018). The term to manage is multifaceted and has several meanings such as to be in charge of, run, supervise, or use resources sensibly (Manage, n.d.). This implies that to manage consists of several elements such as operating, structuring, administrating, controlling, regulating, coordinating, organising, and leading. These are all relevant aspects to consider when designing or delivering care. When designing or executing strategies, it is important to understand the current status and the challenges faced by the organisation (Bamford and Forrester, 2003). The following two sections present some organisational and medical practice challenges faced by the healthcare system today.

\subsection{Organisational challenges in healthcare}

The continuous advances in medical treatment and technical innovations have resulted in a higher focus on improving how to treat and cure diseases, and a lower focus on organisational and managerial aspects of care delivery (Bohmer, 2009, Timmermans and Berg, 2003). These advances have continuously made healthcare and its professionals more specialised and, consequently, have turned the healthcare organisation into a medical specialisation-based structure with independent units, called 'silos' (Coleman and Boult, 2003, Nilsson, 2007). Each silo has separate budgets and performance measurement systems creating incentives for the focus to perform as an internal unit rather than a collective 'organisation' (Plsek and Greenhalgh, 2001). This independence of the units has weakened the links between the units, and is sometimes referred to as fragmentation (Edgren and Stenberg, 2006, Coleman and Boult, 2003, Nilsson, 2007, Bohmer, 2009).

The general consensus is that this organisational structure leads to unclear division of responsibilities, a high need to coordinate between healthcare providers in different silos (hereinafter, providers), and is a barrier for patient-centredness and creating sustainable relationships with patients (Institute of Medicine, 2001, Schoen et al., 2009, Schoen et al., 2011, Fältholm and Jansson, 2008, Glouberman and Mintzberg, 2001). Particular challenges related to unclear division of responsibilities and coordination are the lack of overall responsibility for individual patients due to each silo focusing specifically on their part of care delivery, and where to admit patients who cannot directly be associated with one of the silos (Plsek and Greenhalgh, 2001). This leads to an increased risk of medical errors, service duplication, inappropriate care or patients "falling between the cracks" due to missed communication, and delayed care (Brennan et al., 1991, Coleman, 2003, Coleman and Boult, 2003). Challenges with making care patient-centred are perceived to be partly due to the fact that care is applied based on the providers', and 
not the patients', perspective of what care is needed. The patient is the only one who knows how their disease affects them. Nonetheless, care is first and foremost provided for single diseases and its associated medical needs, and not for the needs expressed by patients. Information on the patient's medical history, experienced symptoms, non-medical needs and preferences therefore sometimes go unnoticed (Killander et al., 1999, RÖ, 2015, Starfield et al., 2003).

\subsection{Challenges in medical practice}

Aside from organisational challenges, there are also challenges affecting medical practice such as patient variation, uncertainty in care delivery, and making medical prioritisations.

The first challenges relates to patient variation and according to Babrow et al. (1998) these variations relate to demographics, medical needs, comorbidities, and preferences for both individual patients and particular patient groups. Few patients seeking care today follow the textbook example of a 'model patient' with clear symptoms, that can be easily diagnosed and treated, after which the patient is discharged completely free of the symptoms or disease. These cases of course still occur, but an increasing number of patients seek care with unclear or ambiguous symptoms such as headache or stomach-ache or with a variety of symptoms which need to be pieced together into one or more diseases (Bohmer, 2009).

Challenges relating to uncertainty in care delivery occur as both scientific and practical uncertainty (Han et al., 2011). Scientific uncertainty concern disease related uncertainties in diagnosis, prognosis, causal explanations, and treatment recommendations (Han et al., 2011, Bohmer, 2009). The distinction between what is normal and abnormal can be hard to make and frequently causes errors such as diagnosing non-existing diseases and misdiagnosing existing diseases (Eddy, 1984). Practice uncertainty concerns how to conduct and organise diagnostics and treatments, or in other words, how to use the processes and structures in the healthcare system (Han et al., 2011). This type of uncertainty causes variation in practice in relation to how to ask about symptoms, observe signs, choose what tests and examinations to conduct, interpret test results, and record answers (Wennberg, 2002).

The last challenge relates to medical prioritisation; how to make justified prioritisations between patients based on their care needs is an internationally recognised problem (Tinghög et al., 2014, Askildsen et al., 2011, Bagshaw et al., 2017). The lack of clear recommendations for making priority decisions has left providers to make their own decisions, prioritising ad hoc (Tinghög et al., 2014). This is problematic since it violates the equity principle (Askildsen et al., 2011) meaning that patients with higher priority should receive care first and patients with equal priority are to be treated equally irrespective of characteristics such as age, gender, income, and ethnicity (Wagstaff and Van Doorslaer, 2000, The Swedish Government Inquiries, 2001, NBHW, 2016). The situation when a patient with lower priority receives care before a patient with lower care priority is called crowding-out (Wilkens et al., 2016).

The previous sections have outlined some challenges faced in healthcare today. The question remains however, as to what has and what can be done to manage care for patients. This thesis, focuses on is patients with complex care needs, and is presented in the next section. Thereafter follows previous research on managing care for patients with complex care needs.

\subsection{Patients with complex care needs}

A group of patients that is perceived to not beneficiate from the traditional healthcare structures and care delivery processes are patients with complex care needs (Thomas-Henkel et al., 2015). Patients with complex care needs are not a well-defined patient group but refer to patients with serious diseases or injuries, chronic diseases, comorbidities, many drugs, mental disorder, frequent hospitalisations, limited ability to perform basic daily functions due to physical, mental or psychosocial challenges and so forth (Schoen et al., 2011, Bodenheimer and Berry-Millett, 2009, Starfield et al., 2003, Condelius et al., 2008). 
Common characteristics are high utilisation of healthcare services and high costs for the healthcare system. These arise from simultaneous involvement in a number of care processes, a need for the involvement of multiple providers, several transitions in the healthcare system, frequent visits to emergency care, and a high number of hospitalisations, for example (Bodenheimer and Berry-Millett, 2009).

A challenge in the healthcare system is how to manage care for these patients. Typically, care delivery for this group is associated with scientific and practical uncertainty due to the ambiguousness of symptoms as well as needs and difficulties in directly observing the cause-and-effect (Chan et al., 2018). This complexity thereby require more extensive strategies where multiple aspects of care are combined such as managing interdependencies between providers, tailoring of care activities, and including social health aspects such as provider-patient communication, to provide sufficient care for these patients (Thomas-Henkel et al., 2015). Previous research also highlight that lack of clear definition of this group makes it difficult identify these patients (ibid).

A patient group that is often referred to as having complex care needs is cancer patients. However not all cancer patients have complex care needs because the needs vary depending on factors such as severity of disease, stage of the care, long-term effects, and, perhaps, combinations with the complex needs presented above (Whelan et al., 1997, Sanson-Fisher et al., 2000). Severity is perhaps the aspect most associated with complexity for cancer patients. A study of patients newly diagnosed with cancer by Sanson-Fisher et al. (2000) however showed that patients experiencing physical and psychological distress related to their disease can also be considered as having complex care needs. For example, for some patients, the way their disease affected them resulted in them becoming too ill to take care of themselves or their home, and they therefore required additional support (ibid). To determine whether a patient has complex care needs, a complete assessment of the physical, psychosocial, supportive, and practical needs is necessary needed. The next section presents some strategies used to manage care for patients with complex care needs.

\subsection{Managing care for patients with complex care needs}

As previously mentioned, compared to improving medical treatment and technical innovations in healthcare, managerial aspects have been overlooked. However, much research is being conducted on managerial aspects of healthcare. This thesis does not strive to outline all possible strategies to manage care, but rather explores some practices that can improve care for patients with complex care needs. Practices in this thesis refer to how an organisation work or the actions taken to achieve something (Sousa and Voss, 2002, Dean and Bowen, 1994). This something can be values or beliefs considered to have significant influence on work in an organisation, sometimes called organisational principles. An example is an organisations belief in work to be process oriented; this can be achieved by the practice process mapping. Since practices define how we work, there is also a need to specify tools and techniques applied in the organisation to actually execute this work, such as flow diagrams for process mapping (Deming, 1991). The next section will present some practices and tools used to deliver care for patients with complex care needs.

\subsubsection{Managing variation and uncertainty}

The description of patients with complex care needs highlights the variation in needs and uncertainties in care delivery. In contrast to how healthcare generally works by reducing patients to single diseases, caring for this patient group necessitates embracing the challenge of variations and uncertainties (Lillrank, 2003). Variations and uncertainties can however be managed by practices aimed at minimising or enhancing their influence on care delivery (Begun and Kaissi, 2004, Eddy, 1984).

The practice standardisation has been extensively described in the literature and is aimed at reducing unwarranted variation (variation that occur 'for no good reason'), and to promote uniformity and 
stability of thoughts, actions and outcomes (Poksinska, 2007, Timmermans and Berg, 2003, Mercuri and Gafni, 2011, Galbraith, 1974). Standardisation can be conducted on individual work tasks or to structure the sequence of work tasks (Mintzberg, 1989). One example of the first type is the standardisation of diagnostic assessment programmes for structured needs and urgency assessment, also called triage (Brouwers et al., 2009, Varley et al., 2016).

Reports of extensive patient safety issues related to unsuitable care processes and practices at an organisational level (Kohn et al., 2000) increased the pressure to make care more structured (Vanhaecht et al., 2010). This led to a growing interest in approaches to structure the sequence of care activities. A process, chain of activities that together create value for a patient (Bergman and Klefsjö, 2010) can in healthcare refer to the operational delivery process conducted by providers and the actual process that patients go through. Process orientation is an example of an organisation-wide approach used to structure the care organisation, change focus towards patient needs, and better match their needs with providers' services (Fältholm and Jansson, 2008, Elg, 2011, Gemmel et al., 2008). Studies have, however, shown that implementing process orientation in healthcare is easier said than done and that silos and the professional organisation are perceived to hinder its implementation (Hellström et al., 2010).

Other approaches used to structure care processes are clinical practice guidelines (Grimshaw et al., 2004) and care pathways (Dubuc et al., 2013, Vanhaecht et al., 2006, Butow et al., 2015). Guidelines are a set of routines describing how to conduct individual or linked care activities (Grol, 2001). Care pathways, on the other hand, are comprised of a multidisciplinary agreed sequence and content of care, based on the latest evidence, and division of responsibility between providers to manage care for populations of patients with a given disease (Vanhaecht et al., 2007, Panella et al., 2012). Several initiatives have been instigated to systematically implement care pathways nationally, for example in cancer care (Wilkens et al., 2016, Probst et al., 2012). In 2015, Sweden started implementing the national improvement programme called Standardised Cancer Care Pathways (CCPs) (NBHW, 2015b). The goal, by introducing CCPs, was to make cancer diagnostics more uniform to achieve more timely, accessible, equitable, and patient-centred care (NBHW, 2015b). CCPs is the umbrella term for the introduction of several strategies such as diagnosis-specific guidelines, introduction of CPPcoordinators (hereinafter coordinators), mandatory reporting of waiting times, and so forth (NBHW, 2015b).

Standardisation is effective in reducing unwarranted variation. Even so, eliminating 'all' variation risks increasing the difficulty of diagnosing or treating individual patients, or risks failure to consider and integrate individual needs (Lillrank and Liukko, 2004, Mercuri and Gafni, 2011). Customisation promotes adaptation of services to respond to specific needs, implying that there is also warranted variation (Lampel and Mintzberg, 1996). Customisation is a well-established concept in manufacturing and is now being translated as a systematic approach in the healthcare context (Chaudhuri and Lillrank, 2013, De Blok et al., 2014), especially in relation to adaption of care processes (Bohmer, 2009).

The relationship between standardisation and customisation has been discussed by several scholars and is seen by some as competing (Mannion and Exworthy, 2017) and by other as complementing logics (Greenfield et al., 2018). Multiple scholars have provided conceptual work on the application of standardisation and customisation in general (Mannion and Exworthy, 2017), on decision making tools (Elwyn et al., 2015), and on care processes (Bohmer, 2005, Bohmer, 2009, Lillrank, 2003, Lillrank and Liukko, 2004, Lampel and Mintzberg, 1996). Some examples of empirical studies on combining standardised and customised activities and processes are available (Essén, 2008). Using patient data, an attempt has also been made to separate patient groups with complex care and to assign different patient groups to different types of processes (De Regge et al., 2015). Mannion and Exworthy (2017) point out that "there remains an urgent need for more sustained work exploring how the competing logics of standardization and customization are articulated, adapted, blended and/or resisted on the front line of 
care delivery" (p. 3). In this thesis, standardisation and customisation are seen as complementing logics which can be used to manage care pathways.

\subsubsection{Managing interdependencies between people and activities}

In previous sections, the silo structure have been pointed out to be a barrier for managing care for patients with complex care needs (Thomas-Henkel et al., 2015). Managing interdependencies between people and activities are thereby considered as an especially important aspect in care delivery for this patient group.

Two studies on the perception of care by patients with complex care needs highlighted coordination not only as one of the most important elements of care but also as the most deficient (Schoen et al., 2009, Schoen et al., 2011). Care provision for this patient group often involves several care activities and transitions between providers and silos (Coleman and Boult, 2003), and a study on patients treated for cancer showed that patients, on average, met 28 different physicians during the first year (Smith et al., 1999). Coordination both between a provider and patient and multiple providers is therefore considered vital to manage interdependencies between people and activities (Goodwin et al., 2013, Bickell and Young, 2001, Capitman, 2003, Holland and Harris, 2007, Malone, 1988, McDonald et al., 2007, Walsh et al., 2011). Integrated care is a growing research topic promoting coordination within and between healthcare units through strategic processes and methods (Cortis et al., 2017, Gröne and GarciaBarbero, 2001). Care coordinators are increasingly used internationally to coordinate internally between providers and externally with patients (Freijser et al., 2015, Lie et al., 2018b, Axelsen et al., 2014, Bayard et al., 1997, Cancer Institute NSW, 2011, Monterosso et al., 2016, Nutt and Hungerford, 2010).

Suggestions have also been made for research on coordination in relation to standardisation and customisation. Mannion and Exworthy (2017) state that "A key tenet of such work, ..., is the absence of a central actor, coordinating processes of standardization (or equally, customization)" (p.3). In this thesis, coordination is perceived to be a complementing practice to standardisation and customisation in managing care for patients with complex care needs.

\subsubsection{Managing provider-patient communication}

Another relevant aspect for managing care for patients with complex care needs are managing providerpatient communication. In addition to coordination, the study by Schoen et al. (2011) also emphasised communication as an important factor but further state that patients are dissatisfied that the communication is not particularly personalised.

The concept, personalisation has been identified in service management literature as a means to achieve personalised communication (Surprenant and Solomon, 1987, Mittal and Lassar, 1996, Gwinner et al., 2005). This concept is still underrepresented in healthcare literature. However, on a conceptual level, Minvielle et al. (2014) discuss potential benefits of personalisation to achieve patient-centred care. De Blok et al. (2013) combine customisation and personalisation to better match the needs and services of individual patients in elderly care, and (Meijboom et al., 2018) to study whether patients experience customisation and personalisation in cancer care. Personalisation is not the only concept that addresses communication. Other related subjects are interpersonal communication theory (e.g. Bylund et al., 2012) and communication in general (Caris-Verhallen et al., 1999, Stein et al., 2005). What differentiates personalisation from more general concepts of communication is its focus on provider-patient relations, and its emphasis that providers match behaviours and communication to the unique and specific needs of the customer (De Blok et al., 2013). Some scholars consider personalisation to fall under customisation (Mannion and Exworthy, 2017). In this thesis, personalisation is seen as a separate practice from customisation since it can be practiced without changing the delivery of the care pathway.

This chapter have highlighted care pathways and the practices coordination, standardisation, customisation, and personalisation as important for managing care for patients with complex care needs. Changing the way care is managed should lead to either a sustained or improved quality of care for these 
patients. The next section discusses how quality of care can be assessed for improvement programs and patients with complex care needs.

\subsection{Quality of care for patients with complex care needs}

A major challenge in healthcare is how to evaluate outcomes and quality of care. Numerous improvement strategies, such as implementing care pathways through the improvement program CCPs, are introduced into healthcare annually. However, for some time scholars have expressed concerns regarding the difficulties of establishing evidence of their ability to achieve the desired results of performance improvement and how this should be estimated (Øvretveit and Gustafson, 2002, Shojania and Grimshaw, 2005).

Quality has been perceived as a difficult concept to define (Donabedian, 1988, Bergman and Klefsjö, 2010) and many definitions and interpretations have been used over the years. In quality management, Bergman and Klefsjö (2010) describe the development as a shift from a narrow industrial control to wider definitions involving customer needs and holistic approaches. The same development can be seen in healthcare where focus has shifted from quality being something that could not, or even should not, be measured, to precise and comprehensible measurements (Donabedian, 1988), and subsequently to shift again to value perceived by a patient (Epstein and Street, 2011, Porter, 2008).

Opinions differ as to what perspective on quality of care should be assessed, whether it is that of the patients or the providers. Even though quality of care from the patient's perspective is important, retrospectively asking patients has been shown to be problematic. In the moment when the care activity takes place, patients do not necessarily focus on whether they received patient-centred care and this may cause them to misremember or to be biased because of other experiences (Brook et al., 2000). However, assessing care from the provider perspective is also challenging. In many cases, it is hard to measure improvements, for example in the quality of care, as measures such as waiting times do not tell the whole truth (Øvretveit and Gustafson, 2002). This is why researchers need to consider performance as perceived by healthcare professionals.

Several attempts have been made to outline dimensions of quality of care (Campbell et al., 2000, Institute of Medicine, 2001, Donabedian, 1990, Maxwell, 1992, WHO, 2006, Beattie et al., 2013). Although the literature on these dimensions is extensive, both the number and the types of dimensions differ. The most commonly used dimensions are outlined by the Institute of Medicine: safety, timeliness, effectiveness, efficiency, equity and patient centeredness (Institute of Medicine, 2001). Effectiveness refers to knowledge-based and suitable care; doing the right things, efficiency to resource efficiency; doing things right, and patient-centred to a care based on patient needs, values, and preferences (Institute of Medicine, 2001, NBHW, 2006). Accessibility is a multifaceted term referring to geographical or physical accessibility and availability of services; timely care delivery refers to receiving appropriate care at the right time; and equitable care delivery to having equal access to care (Campbell et al., 2000).

Attempts have been made to generalise the effectiveness of different care pathway programmes. However, the widely varying definitions and components have made it difficult to draw general conclusions on their effectiveness (Ouwens et al., 2005). The problems are not surprising considering the variety of improvement initiatives implemented, both in terms of content and purpose (Dahlgaard et al., 2011). For example: New Karolinska Solna is an example of a reorganisation of a hospital to enhance patient-centredness (e.g. Sundström, 2018); the CCP is a national improvement programme to improve timeliness, increase equity and improve patient satisfaction in cancer care (Wilkens et al., 2016, Schmidt et al., 2018); pivot nursing is a new triage methodology to improve timeliness in an Emergency Department (Christensen et al., 2016). The difficulty lies in that improvement initiatives are dynamic, and the content and scope vary dependent on the context, so for the assessment to be informative, several factors that could influence the end result need to be considered. The differences in complexity and focus thereby enhance the unlikeliness that the dimensions of interest are exactly the same in each case. 
Scholars have stated that evaluations of quality of care are scarce (Pearson et al., 1995) and highly anecdotal (Campbell et al., 1998). The general perception is, however, that care pathways seem to have positive effects on the quality of care. This have been studied in terms of for example patients' perception of patient centredness and coordination (Bayliss et al., 2008), providers' perception of coordination (Coleman, 2003, Coleman and Boult, 2003, Gittell et al., 2000), timeliness (Jensen, 2015), effectiveness (Bodenheimer and Berry-Millett, 2009, Coleman, 2003, Coleman and Boult, 2003), and patient-measured medical outcomes (Coyle and Battles, 1999, Cheah, 2000). Studies on quality of care associated with patients with complex care needs also show that there is a high risk of complications and problems such as difficulties to access the healthcare system (Jensen, 2015), lack of appropriate health assessment (Min et al., 2005) and lack of knowledge of the patient's inclusion in parallel care processes, treatments and medications (Simon et al., 2005). In the following section, the purpose and research questions of this thesis are presented.

\subsection{Purpose and research questions}

Previous sections have described patients with complex care needs as requiring a holistic perspective on patient care (Bodenheimer and Berry-Millett, 2009, Starfield et al., 2003, Bird et al., 2007, Poksinska, 2018, Schoen et al., 2011). Care pathways are perceived as an effective means to achieve this (Sermeus et al., 2005, Vanhaecht et al., 2010). Based on the challenges and background described in the previous sections the purpose of this thesis is to:

\section{contribute with knowledge on how care pathways can be managed for patients with complex} care needs.

Coordination, standardisation, customisation, and personalisation have also been identified as practices used to manage care pathways for patients with complex care needs. The definitions of these practices used in this thesis are:

- Coordination: Managing interdependencies between people and activities

- Standardisation: Making care pathways uniform or predictable

- Customisation: Adapting care pathways to individual needs

- Personalisation: Adapting behaviour or communication to individual needs

Bringing these concepts together could contribute to a more holistic care approach for patients with complex care needs.

The first research question is thus:

1. How can care pathways be managed using the practices coordination, standardisation, customisation, and personalisation for patients with complex care needs?

Changing the way healthcare is managed is not a guarantee for improved care, and it is important to also consider how these practices could influence the quality of care for these patients. Based on the background of quality of care as presented in the previous section, the quality of care dimensions were selected following a combined review of the dimensions considered to be important for patients with complex care needs, and the aim of the improvement programme CCPs, which is the empirical context in this thesis. The chosen quality of care dimensions are accessible, timely, equitable, and patient-centred care. 
In this thesis, these dimensions are defined as:

- Accessible: Availability of and access to services

- Timely: Receiving care at the right time

- Equitable: Sufficient care provided to each patient to meet their individual needs

- Patient-centred: Providers strive to identify, respect, and manage patient needs, invite patients to actively participate in care, and deliver individually customised information.

The second research question is thus:

2. How can these practices influence the quality of care?

To the best of this author's knowledge, there is no study that combine these four practices with care pathways for this patient group. Empirical data from the improvement programme CCPs are applied to illustrate how these practices can be used to manage care for patients with complex care needs and how they influence quality of care for patients with complex care needs.

\subsection{Outline of the thesis}

\section{Chapter 2 presents Empirical context}

Chapter 3 presents Theoretical framework

Chapter 4 presents Methodology

Chapter 5 presents Overview of appended papers

Chapter 6 presents Analysis and discussion

Chapter 7 presents Conclusions, contributions and future research 


\section{Empirical context}

The aim of this chapter is to present the empirical context studied in this thesis - standardised cancer care pathways. The following section presents a short overview of the Swedish healthcare system. Thereafter follows a description of Swedish cancer care with the focus on the improvement programme Standardised Cancer Care Pathways.

\subsection{The Swedish healthcare system}

The Swedish Healthcare Act is the overarching document governing Swedish healthcare. The act states that the aim of healthcare is to provide good health and care on equal terms for the entire population (Government Offices Of Sweden, 1982). Further, it states that the responsibility for Swedish healthcare is divided between the government, healthcare regions (hereinafter, regions), and municipalities. The government has the overall responsibility for establishing principles and guidelines and setting the policy agenda (ibid). The 21 autonomous regions are politically governed organisations. The regions are responsible for organising healthcare for its residents based on its own local needs and the guiding principles set by the government (Anell, 2005). A region can be divided into primary, secondary, psychiatric, and dental care. Finally, the 290 municipalities are responsible for community care such as elderly care and care for patients with physical or psychological disabilities (ibid).

This section provides an overview of the actors involved at different levels in the Swedish healthcare system. The next section first provides an overview of the overall context, Swedish cancer care, before presenting the empirical context in this thesis, standardised cancer care pathways.

\subsection{Swedish cancer care}

Cancer is one of the most common diseases in Sweden. In 2016, more than 60,000 people were diagnosed with cancer in Sweden and it is estimated that at least every third person will develop cancer during their lifetime (The Swedish Cancer Society and NBHW, 2018). Usually, Swedish cancer care is ranked highly in international comparisons of care outcomes (SALAR, 2015). Even so, the increasing number of cancer patients poses major challenges to the healthcare system (Wilkens et al., 2016). Swedish cancer care is executed by the regions and constitutes all care levels; it is mainly executed by primary and secondary care providers and involves multiple care specialities. Care outcomes are followed up nationally through cancer registers and quality registers (Barlow et al., 2009).

The first Swedish National Cancer Strategy was published in 2009 by The Swedish Government Inquiries and presented the direction of future cancer care (SOU, 2009). Challenges of Swedish cancer care were mapped, such as unacceptably long waiting times, lack of accessibility to cancer care and lack of information and care coordination (SOU, 2009). A number of recommendations in various areas were presented, for example increasing the use of administrative support functions for coordinators and medical secretaries, clarifying responsibilities within and between specialisations and regions, and monitoring waiting times in the care process. Since then, a number of improvement programmes have been launched to improve cancer care, such as the 'Queue-billion', a reward system to reduce waiting lists, and CCPs (Wilkens et al., 2016). An overview of the CCPs will be presented in the next section.

\subsection{Standardised Cancer Care Pathways}

To face the challenges of long waiting times, regional differences and fragmented care processes, the Swedish government invested SEK 500 million annually during the period 2015-2018. This was dedicated to implementation of the improvement programme CCPs in cancer care (NBHW, 2015b). Additional funds have been invested in 2019 and the programme has been extended to 2020 (NBHW, 2018). All regions in Sweden joined the improvement programme and were assigned responsibility to 
implement and adapt the CCPs in their local setting. If the regions fulfil the requirements, they receive a part of the financial resources assigned by the government (NBHW, 2018).

National expert groups developed CCPs for 31 cancer diagnoses by following the Danish example, pakkeforløb. Simplified, a CCP is an extended guideline specifying how to deliver care for individual cancer diagnoses (or a group of similar cancer diagnoses) (Wilkens et al., 2016). Each diagnosis has its own CCP-guideline containing information about symptoms indicating cancer, a list of tests and examinations to be performed, maximum time limits for each step in the care process, information that should be given to patients, need for multidisciplinary meetings, and treatment options.

The aim of the CCP is not to improve the complete care process. Instead, focus is on the initial part of the care process, from when cancer is suspected until the start of the first treatment. Suspicion of cancer is based on a set of indicators and test results which indicate a well-founded risk of cancer, and usually arise in the primary, emergency, or secondary care services. Indicators, or alarm symptoms, have been individually developed for each cancer diagnosis to indicate the type of cancer for which diagnostics should be conducted (NBHW, 2015b). If a cancer is confirmed, a treatment plan is drawn up and the $\mathrm{CCP}$ ends at the start of the first treatment. To ensure timely care, maximum waiting time limits are specified for some parts of the care pathway such as a maximum waiting time to see a physician, for a case to be addressed at multidisciplinary conference, and for start of first treatment. Multidisciplinary conferences are regular meetings, typically diagnosis-specific, where providers from different specialties and professions meet to analyse results of tests and examinations and discuss preliminary treatments for patients (ibid).

Implementing CCP-guidelines and improving routines for diagnostics are the most central elements of the CCP improvement programme. Additional efforts are also required by the regions such as setting up measurement systems for follow-up waiting times, pre-schedule appointments for CCP-patients, and introducing a new role, CCP-coordinator (hereinafter coordinator) (ibid). The pre-scheduled appointments are timeslots reserved for CCP-patients to ensure accessibility to appointments (Wilkens et al., 2016). The coordinator is an administrative role, working to support healthcare professionals with administrative tasks and ensure that unnecessary waiting times are avoided in the care process (NBHW, 2016). According to a nationally developed written work statement, the primary tasks are (RCC, 2017):

- ensure information flow between providers and patients

- act as a contact person towards general practitioners and emergency departments

- conduct administrative tasks such as scheduling appointments, monitoring and followingup lead times

- scrutinise incoming referrals

- ensure cooperation and collaboration between providers in different parts of the healthcare system and

- support safe transitions for patients moved between the different sections of the healthcare system.

When the improvement programme CCPs was extended in 2018, the focus changed from implementing CCP-guidelines and routines to creating sustainable processes and endeavouring to achieve the nationally set goals for maximum waiting times. These goals are: $70 \%$ of all cancer patients should follow a CCP, and $80 \%$ of these patient should receive care within the maximum time limits (NBHW, 2018). 


\section{Theoretical framework}

This chapter presents important theoretical concepts that frame this thesis. The first section outlines quality of care and the Quality of Care Framework. The second and third sections describe the practices coordination, standardisation, and customisation. The fourth section describes care pathways and the last section describes the practice personalisation.

\subsection{Quality of care}

In the background of this thesis, the difficulties of evaluating quality of care was presented. As previously mentioned, some of the reasons for the difficulty in defining quality, might be that it is contextual, subjective (Dahlgaard et al., 2011) and is influenced by the scope and perspective to be applied (Donabedian, 2002). In the following section, the Quality of Care Framework used to evaluate research question 2 is presented.

\subsubsection{Quality of care at different levels}

Reasoning that quality of care is context dependent, Donabedian (1988) describes quality of care at three levels: patient, community, and provider. At patient level, care quality is assessed through the care actually received by the patient, where the provider and the patient and her/his relatives share the responsibility for the care experience. At the community level, quality depends on performance of care services for the whole community relating to who gains access and what quality of care each patient receives (ibid). Quality of care at the provider level depends on the performance of the service providers such as physicians, nurses, and coordinators (ibid). The technical dimension is thereby reliant on the fruitfulness of the functional dimension to produce accurate outcomes (Grönroos, 1984, Donabedian, 1988).

In this thesis, services are perceived to be co-created by providers and patients and is delivered to individual patients. This is why the individual patient's perspective is thus important to assess quality of care (Campbell et al., 2000). In addition, the ultimate goal of healthcare is to provide high quality care to the whole population. This indicates that delivered services will affect the outcome not only for individual patients but also for populations of patients. Because the population perspective might be different to that of individual patients, this perspective is also interesting when evaluating quality of care (Campbell et al., 2000). The next paragraph presents the categories structure, process and outcome from which quality dimensions can be derived.

\subsubsection{Assessing quality of care through structure, process and outcome}

In addition to deciding the level at which quality of care should be assessed, there is also a need to derive what should be assessed. Donabedian (1966) suggests that the dimensions to be assessed can be derived from the three categories: the organisational structure of the healthcare system, the care delivery process, and care outcome.

Structure refers to the physical and organisational setting in which care delivery occurs and includes elements such as formal and informal structure, human resources, material resources (1966), and organising principles (Scott, 2015). Healthcare is a complex system with ever-changing constellations of units, functions, specialisations, staff (both medical and non-medical), physical sites, equipment and so forth which all may affect the quality of care delivery (Plsek and Greenhalgh, 2001). Beside these more 'obvious' elements of structure there are also other less apparent ones such as organising principles. Organising principles can be described as fundamental truths or generalisations which provide organisations with instructive and predictive values and behaviours on which to base decisions and actions (Koontz, 1961). One example from the quality management literature is the principle process orientation. Process orientation can be used to shift focus from product to process characteristics in order to improve performance of services (Davenport, 1993). Organisations working with process orientation 
are characterised by cross-functional work, customer orientation, and a system focus to meet the customer need (ibid).

To understand the quality dimensions which can be derived from a process there is first a need to understand what a process is (ibid). There are several definitions of a process, and in this thesis a process is described as a chain of activities that together create value for a patient (Bergman and Klefsjö, 2010). In a nutshell, a care process can be described to consist of a number of activities performed by different care providers to achieve the goal of delivering appropriate services to a patient (Malone, 1988). In healthcare, the care process is always triggered by the inputs (needs) of the customer (patient), and it is primarily the needs that determine the course of the care process. Palmberg (2009) divides processes into three categories: strategic management processes, operational delivery processes, and supportive administrative processes. In this thesis, the processes in focus are those directly related to patient care i.e. operational care delivery processes conducted by providers. It includes the management of clinical care processes and its sub-processes, service events and activities (Wiger, 2018), necessary preparations (such as booking of appointments), and inter-personal care but disregards medical considerations. The patient care process is the chain of service episodes that together form the care process that the patient goes through, for example during cancer diagnostics.

Outcome, according to Donabedian (1966), include quality dimensions related to the perceived effects of care on a patient's or population's health status or their experience of the care process. Typically, the quality related to outcomes is the result of several quality dimensions which, when perceived by the patients, can be divided into technical and functional quality (Grönroos, 1984, Donabedian, 1988). Technical quality is the result of the process or service performed by the provider; i.e. what or the outcome that the patient receives which is the effect of the know-how in the organisation such as its services and abilities (Grönroos, 1984). Functional quality is the way that a service is delivered to a patient; how or the process by which the technical quality is produced (Grönroos, 1984, Donabedian, 1988). An important part of the functional dimension is a provider's interpersonal traits on which the ability to communicate with patients to access and mediate information depends (Donabedian, 1988). Examples of technical quality are clinical measures and patient reported outcome measures, and functional quality are patient-reported experience and satisfaction measures (Poksinska et al., 2014).

In this thesis, focus is not on improving medical aspects of care and treatment (not directly) or on measuring patients' satisfaction with care but on improving care processes and structure (e.g Batalden and Stoltz, 1995). Thus, both medical outcomes and patient satisfaction are out of scope. Instead, the outcomes evaluated in this thesis is performance measurements of the care processes and structure. These measures can be derived from the means, of the process and structure, by which care is delivered (Donabedian, 1966). Outcomes of such measures are for example accessibility, appropriateness, and timeliness of services (Campbell et al., 2000). Many authors (Donabedian, 1990, Maxwell, 1992, WHO, 2006, Beattie et al., 2013) have discussed which elements define quality of care; for example Campbell et al. (2000) provide a taxonomy which includes 11 dimensions of quality, and The Institute of Medicine (2001) defines six dimensions, which have already been presented in the background of this thesis: safety, timeliness, effectiveness, efficiency, equity and patient centredness. Based on an extensive review of quality dimensions Beattie et al. (2013) proposed that caring and navigating the healthcare system should also be added to the list of quality dimensions.

\subsubsection{Quality of Care Framework}

To summarise, in this thesis, quality of care is assessed through the providers performance that aim to improve care for individual patients and populations of patients. To do so, quality dimensions are derived from performance measures from the structure and the process. Figure 1 illustrates the Quality of Care Framework developed in this thesis. 


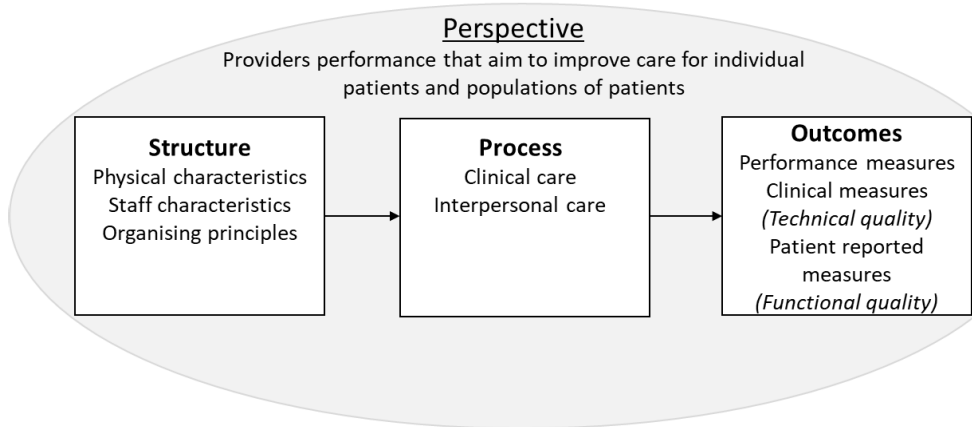

Figure 1: The Quality of Care Framework used in this thesis (based on Donabedian (1966) and Batalden and Stoltz (1995).

\subsection{Coordination}

A challenge in most organisations is how to manage interdependencies between actors and activities. In cases with multiple actors or activities, the need for additional structures or organising activities such as planning, information exchange or follow-ups, often arise (Malone, 1988, Mintzberg, 1980) due to shared resources between actors and/or reciprocal sequential dependencies between work activities (Stabell and Fjeldstad, 1998). It is these activities that are intended as a means to achieve coordination (Malone and Crowston, 1994). The need for coordination is argued to increase in organisations such as healthcare organisations (Glouberman and Mintzberg, 2001) with high differentiation between actors in terms of goals, structures, and interpersonal distance (Lawrence and Lorsch, 1967). There is no unified definition of coordination in healthcare. In this thesis, care coordination is defined as the careful organisation of a patient's care process conducted by involved providers, in agreement with the patient and the patients needs and preferences (McDonald et al., 2007). In addition to the organisation between actors, this definition also emphasises that patients too should be involved in coordination.

Coordinating tasks, or coordination mechanisms, are separated from the production-related activities that constitute the operational delivery process, and instead are seen as enablers for efficient and highquality processes (Malone, 1988, Mintzberg, 1980). A vast number of coordination mechanisms is mentioned in the literature, such as boundary spanners, interpersonal communication, and standardisation of work, outputs, and skills (Mintzberg, 1989). The aim of these mechanisms is twofold, either they can facilitate interaction between actors, or they can reduce the need of interaction between actors (Hoffer Gittell, 2002). Boundary spanners are roles, either with decision-making powers such as managers, or without such as liaison roles, aimed at facilitating interaction between actors by giving special attention to coordination (Mintzberg, 1989). In healthcare, care pathways have become increasingly used as a mechanism to standardise work processes, and can be used to reduce the need for interaction between actors by clarifying activities included in the operational care delivery process, and dividing activities and responsibilities between providers (Sermeus et al., 2005).

A term often related to, and even used interchangeably with coordination is continuity. Continuity is defined as a patient's (or sometimes provider's) experience and perception of care integration and coordination over time (Holland and Harris, 2007, Haggerty et al., 2003). Haggerty et al. (2003) describe three types of continuity: informational, management and relational. Informational continuity entails an ongoing flow of information throughout the care process that should be both transferred and taken into consideration by providers and applied in care activities (ibid). Vital information is for example personal information about the patient's preferences, wishes, and requirements and information about the specific disease (ibid). To achieve management continuity all involved providers need to agree on the care process to be carried out and jointly strive towards delivering timely and interconnected care (ibid). 
Relational continuity refers to a long-term relationship between the providers and the patients which extends to include future care occasions (ibid). The descriptions above suggest that managerial and informational continuity is carried out by providers, while relational occurs in interaction between a patient and providers. This implies that the patients' and providers' perspective of continuity differs. For patients it is the security of a continuous dialogue and relation with providers as well as a perception of agreement and mutual planning between providers (Nazareth et al., 2008). For providers it is the notion of having sufficient knowledge and information about the operational delivery care process to provide adequate care, which is also accepted and further operationalised by the other care providers (Haggerty et al., 2003).

\subsection{Standardisation and customisation}

Standardisation is a multifaceted concept that can be used for products (objects), work processes, tasks, measurements, outcome documentation, and so forth (Poksinska, 2007). It is widely applied in healthcare through common terminology, clinical practices, pathways, methodologies for gathering and evaluating data, and so forth (Timmermans and Berg, 2003). In the early stages of healthcare standardisation, emphasis was on elements surrounding medical work, such as standardising skills, methodologies and tools, and not on standardising the content of care (ibid). Now, special emphasis on standardisation in healthcare is placed on evidence based medicine (Sackett and Rosenberg, 1995), and is often compiled into guidelines or pathways summarising present diagnostic and therapeutic knowledge within a certain area (Timmermans and Berg, 2003). In this thesis, standardisation is described as a means used to specify how individuals and organisations should behave or how something should be performed (Ishikawa, 1990) and replicated in the future (Cargill, 1989). Standardisation is thereby seen as a practice that can be used to make the operational delivery process more unified and predictable by reducing the variability of care practice.

Customisation, or sometimes mass customisation (e.g. Chaudhuri and Lillrank, 2013), stems from research in product design and operations management and is a means to tailor products and services to independent customers (Fogliatto et al., 2012, Lampel and Mintzberg, 1996). The definition of customisation according to Pine (1993) is the modification of products and services to meet customers' individual needs. Customisation can be achieved in two ways. The first is to provide a variety of services for each need which can be combined into a service package, and the second is to add or subtract services from an otherwise more or less standardised design (Voss and Hsuan, 2009). The focus on customisation in healthcare emerged along with a shift towards making care delivery more patient-centred (Barry and Edgman-Levitan, 2012). Customisation adapts the patient care process based on physical, psychosocial, supportive, and practical needs.

Like standardisation, customisation in seen as a practice used to adapt a patient's care process to his/her individual needs and is operationalised by the customised care pathway. The next section presents care pathways followed by three frameworks on standardised and customised care pathways.

\subsection{Care pathways}

The idea of pathways evolved from industrial processes in the 1980s as a way to plan care for patients with the same diagnosis, and to make care more patient-centred (Zander, 2002). The function of pathways varies between settings, countries, area of use, and so forth (Vanhaecht et al., 2006, Vanhaecht et al., 2010). There are many names for pathways such as clinical (Butow et al., 2015), critical (Dy et al., 2005), integrated, or short care pathways (Sermeus et al., 2005) (hereinafter called care pathways). There is therefore no agreed name for or even definition of care pathways. One definition, which has been adapted by the European Pathway Association, is "A care pathway is a complex intervention for the mutual decision making and organisation of care processes for a well-defined group of patients during a well-defined period"(Vanhaecht, 2007, pp. 137-138). A care pathway is a plan (often a 
guideline) describing care activities to be included in diagnostics and treatment of a particular disease (Sermeus et al., 2005). In addition, care pathways can, for example, specify a recommended sequence of care activities to improve the methodology of diagnostics for healthcare staff working in the front line (ibid). The care pathways are often quite detailed and include activities to involve patients, multidisciplinary teamwork and suggestions for examinations, tests, coordination, and treatments based on evidence based medicine (Sermeus et al., 2005, Campbell et al., 1998, Zander, 2002). The aim of care pathways is to create predictable care processes that are agreed upon by involved providers (ibid).

Vanhaecht et al. (2010) describe four types of care pathways associated with different levels of the healthcare system. The most aggregated level, international, national or regional level, is the model pathway; often an organisationally independent policy document or guideline based on international or national evidence based medicine. Furthermore, the operational pathway is located at the local level and is a deconstructed and adapted version of the model pathway developed to fit the setting in a specific organisation. Next, the assigned pathway and completed pathway can be found at the patient level, where the assigned pathway is a modification of the operational pathway and has been planned and assigned to a patient to fit his/her individual needs; and the completed pathway is the actual pathway that the patient goes through. The final care pathway is the completed pathway and is the 'map' of the conducted care process; in this thesis it is labelled as the patient care process. To realise the different care pathways there is a need for a chain of translations from national policy down to clinical practice (Elg et al., 2016).

The next section presents the practices standardisation and customisation and the three frameworks describing standardised and customised (organisational models) care pathways. In this thesis, a care pathway is seen as a tool that can be adapted to become more standardised or customised based on the input and complexity of required service episodes and activities. Thereafter, sections on the managing care pathways and personalisation are presented.

\subsubsection{Managing care pathways}

There are several frameworks (e.g. Levitt, 1976, Lovelock and Gummesson, 2004, Lampel and Mintzberg, 1996) that can be used to manage care delivery. In the next sections, three frameworks will be described. The frameworks all show similarities with care pathways as they provide a structure for how to manage operational delivery processes. The following sections describe frameworks on standardised and customised operational process delivery.

In practice, few organisations work according to only one of the standardised or customised care pathways. All frameworks presented below place their frameworks on the standardisation-customisation continuum (e.g. Essén, 2008). This continuum has been used for a long time to describe the differentiation in solutions which range from well-structured processes with uniform outcomes, symbolising predictability and consistency, to innovative processes adapted to customer needs, symbolising flexibility and innovation (Levitt, 1976, Lovelock and Gummesson, 2004). Organisations can place themselves on the outer ends of the continuum, somewhere in between, or try to set up operations which can do both (Lampel and Mintzberg, 1996, Lillrank, 2002, Bohmer, 2009). Hybrids are more common, where the type of product or service determines where on the standardisationcustomisation continuum they act (Lillrank and Liukko, 2004, Stabell and Fjeldstad, 1998). No matter which model is used, the organisation needs to decide on the level of standardisation and customisation applied as it is not unlikely that a standardised process has elements of customisation, and vice versa (Lillrank, 2003).

\section{Standardised care pathway}

The frameworks describing a standardised care pathway are the sequential process by Bohmer (2009), standard and routine processes by Lillrank (2003) and Lillrank and Liukko (2004), and value chain by Stabell and Fjeldstad (1998). A summary of the standardised care pathway characteristics is presented in Table I. 
Table I: Summary of characteristics of the standardised care pathway

\begin{tabular}{|c|c|c|c|c|}
\hline Characteristics & $\begin{array}{c}\text { Bohmer (2005) } \\
\text { Sequential process }\end{array}$ & $\begin{array}{c}\text { Lillrank } \\
(2003 ; 2004) \\
\text { Standard } \\
\text { process }\end{array}$ & $\begin{array}{c}\text { Lillrank } \\
(2003 ; 2004) \\
\text { Routine process }\end{array}$ & $\begin{array}{c}\text { Stabell and } \\
\text { Fjeldstad (1998) } \\
\text { Value chain }\end{array}$ \\
\hline Process input & Low variation & Predefined input & $\begin{array}{l}\text { Input with known } \\
\text { bounded variation }\end{array}$ & Standardised input \\
\hline Scope of service & Narrow & Single variety & Few varieties & Few varieties \\
\hline $\begin{array}{r}\text { Approach to input } \\
\text { variation (v) / } \\
\text { service uncertainty } \\
\text { (u) }\end{array}$ & $\begin{array}{l}\text { V: Eliminate } \\
\text { variation } \\
\text { U: Reduced before } \\
\text { care commences }\end{array}$ & $\begin{array}{l}\text { V: Eliminate } \\
\text { special cause } \\
\text { variation }\end{array}$ & $\begin{array}{l}\text { V: Eliminate non- } \\
\text { warranted variation }\end{array}$ & $\begin{array}{l}\text { V: Selective } \\
\text { differentiation } \\
\text { possible }\end{array}$ \\
\hline Production logic & Sequential & $\begin{array}{l}\text { Identical } \\
\text { repetition }\end{array}$ & $\begin{array}{l}\text { Limited variety of } \\
\text { linked activities }\end{array}$ & Sequential \\
\hline $\begin{array}{r}\text { Care delivery } \\
\text { process }\end{array}$ & $\begin{array}{l}\text { Follow best practice } \\
\text { standards }\end{array}$ & $\begin{array}{l}\text { Follow } \\
\text { standardised } \\
\text { procedures }\end{array}$ & $\begin{array}{l}\text { Decision rules } \\
\text { based on input } \\
\text { classification }\end{array}$ & $\begin{array}{l}\text { Matching input and } \\
\text { standard activities }\end{array}$ \\
\hline Coordination need & & & & Between activities \\
\hline $\begin{array}{c}\text { Resources }(R) \text { and } \\
\text { knowledge }(K) \text { of } \\
\text { providers needed }\end{array}$ & $\begin{array}{l}\text { R: Explicit, high } \\
\text { capacity utilisation } \\
\text { K: Novice, } \\
\text { specialised }\end{array}$ & R: Specialised & $\begin{array}{l}\text { K: Novice, some } \\
\text { experience }\end{array}$ & $\begin{array}{l}\text { R: Standardised } \\
\text { K: Specialised }\end{array}$ \\
\hline
\end{tabular}

The standardised care pathway has a narrow scope (Bohmer, 2009) due to its low variation in input, which in some cases is allowed to vary within set tolerances (Bohmer, 2009, Stabell and Fjeldstad, 1998), and its specialisation in handling predefined input (Stabell and Fjeldstad, 1998). Any uncertainty or variation regarding input should be resolved before the care pathway is initialised (Bohmer, 2009). Activities are performed in a fixed sequence of repetitions which are either identical every time (Lillrank, 2003) or chosen according to the problem at hand (Lillrank and Liukko, 2004, Bohmer, 2009). Matching between input and activities is a verification procedure conducted through matching input and standard activities (Stabell and Fjeldstad, 1998), by following standardised procedures (Lillrank and Liukko, 2004, Bohmer, 2009), or rule application (Lillrank and Liukko, 2004). The work is guided by the aim of reaching the predefined outcome, 'target', by finding the best practice for conducting each activity (Lillrank and Liukko, 2004). Best practice can be described in manuals and standards (Lillrank and Liukko, 2004). The coordination need between activities can be standardised and depends on the nature of the interdependence (Stabell and Fjeldstad, 1998). Errors occur in the process due to insufficient assessment or the choice of activity (Lillrank and Liukko, 2004). Resources needed can be standardised and limited to those necessary for the activities (Lillrank and Liukko, 2004, Bohmer, 2009), and the workers do not need a lot of experience but rather specific knowledge on input or activities (Lillrank and Liukko, 2004, Bohmer, 2009, Stabell and Fjeldstad, 1998). The next section presents the characteristics of the customised care pathway.

\section{Customised care pathway}

The frameworks describing a customised care pathway are the iterative pathway by Bohmer (2009), non-routine pathway by Lillrank (2003) and Lillrank and Liukko (2004), and value shop by Stabell and Fjeldstad (1998). A summary of characteristics of the customised care pathway is presented in Table II. 
Table II: Summary of characteristics of the customised care pathway

\begin{tabular}{|c|c|c|c|}
\hline Characteristics & $\begin{array}{c}\text { Bohmer (2005) p. 84, } \\
128-129 \\
\text { Iterative care process }\end{array}$ & $\begin{array}{c}\text { Lillrank }(2003,2004) \\
\text { Nonroutine care process }\end{array}$ & $\begin{array}{c}\text { Stabell and Fjeldstad } \\
(1998) \\
\text { Value shop }\end{array}$ \\
\hline Process input & Random, high variation & $\begin{array}{l}\text { Non predictable or easily } \\
\text { classifiable, vague }\end{array}$ & Unique \\
\hline Scope of service & Individual adaption & Wide set of solutions & Individual adaption \\
\hline $\begin{array}{r}\text { Approach to input } \\
\text { variation (V) / } \\
\text { service uncertainty } \\
\text { (U) }\end{array}$ & $\begin{array}{l}\text { V: Exploit for learning } \\
\text { U: Reduce during care }\end{array}$ & V: Accept variation & $\begin{array}{l}\text { V: Exploit to develop } \\
\text { new services }\end{array}$ \\
\hline Production logic & $\begin{array}{l}\text { Exploratory, several } \\
\text { iterations }\end{array}$ & Iterative & Iterative, cyclical \\
\hline Care delivery process & $\begin{array}{l}\text { Unstructured problem } \\
\text { solving }\end{array}$ & Iterative reasoning, learning & $\begin{array}{l}\text { Cross-case learning } \\
\text { and problem solving }\end{array}$ \\
\hline Coordination need & & & $\begin{array}{l}\text { High coordination need } \\
\text { (coordination roles, } \\
\text { cross-functional team) }\end{array}$ \\
\hline $\begin{array}{r}\text { Resources }(R) \text { and } \\
\text { knowledge }(K) \text { of } \\
\text { providers needed }\end{array}$ & $\begin{array}{l}\text { R: Low capacity } \\
\text { utilisation } \\
\text { K: Tacit, expert }\end{array}$ & $\begin{array}{l}\text { R: Capacity for problem } \\
\text { solving } \\
\text { K: Experience, tacit } \\
\text { knowledge, organisational } \\
\text { 'team' culture }\end{array}$ & $\begin{array}{l}\text { R: Labour intensive } \\
\text { K: Specialised, expert }\end{array}$ \\
\hline
\end{tabular}

This pathway aims to solve individual customer problems that can have a high (Bohmer, 2009) and unpredictable variation in input (Lillrank, 2003) and which are highly dependent on the customer and problem to be solved (Stabell and Fjeldstad, 1998). This pathway accepts all, or most, kinds of input and does not reject input for which there is yet no solution (Lillrank, 2003). Instead it takes advantage of the variation to learn (Bohmer, 2009) and develop new activities (Lillrank, 2003, Stabell and Fjeldstad, 1998). Lack of a clear problem description, or symptomatology, or directly applicable solutions open up for exploratory problem solving or trial-and-error which can be used in an iterative (Lillrank, 2003, Bohmer, 2009) and/or cyclic manner (Stabell and Fjeldstad, 1998) until the problem is found or resolved. The output is a customised care pathway. The nature of the work related to customisation implies a high coordination need to manage the interdependencies between activities which can be resolved by coordination roles, lateral integration mechanisms, and full-time crossfunctional teams, for example (Stabell and Fjeldstad, 1998). It is a labour intensive work model (Stabell and Fjeldstad, 1998) with a high demand for skill, experience, tacit knowledge, and intuition among the personnel (Lillrank and Liukko, 2004). In this pathway, cross-case learning is important to gain knowledge for future problem assessments and pathway development (Stabell and Fjeldstad, 1998, Lillrank and Liukko, 2004). The next section presents the practice personalisation.

\subsection{Personalisation}

One big difference between the delivery of services and products is the active role of staff in service delivery (Gwinner et al., 2005). Especially in healthcare, close interactions between service providers and patients are important to both customise and personalise a service (ibid). The practice personalisation originates from service marketing and management to meet customer desires to codesign, co-produce and modify services to fit individual customer needs (De Blok et al., 2013). Rose (2013) describes personalisation as a new paradigm not only in healthcare but also in society as a whole 
where "the individual's uniqueness is recognised and respected" (p. 351). However, critics of this view of personalisation claim that this is not new in healthcare, and that care has always been personalised (Rose, 2013). In this thesis, personalisation is seen as a rather weak aspect of care delivery in which inclusion of the patient's preferences and non-medical needs is not something that occurs naturally.

Unlike customisation, which specifies what service (content) should be delivered, personalisation specifies how a provider should act in interactions with patients (De Blok et al., 2013). Voss and Hsuan (2009) define personalisation as the activity when a provider, after consulting a customer (patient), adapt the way the service activity is delivered based on the patient's expressed or implied needs. Personalisation of services is achieved by the adaptiveness of front-line staff regarding two areas: interpersonal communication and service offerings (Gwinner et al., 2005). It can be conducted during the planning of the service (Piller, 2007, De Blok et al., 2013) or during service delivery (Voss and Hsuan, 2009), but its content is dynamic and may change over time.

Application of personalisation is often suggested as a complement to customisation to achieve more patient-oriented care (De Blok et al., 2013) and to increase patient satisfaction (Gwinner et al., 2005, Meijboom et al., 2018). However, applying one does not automatically imply the application of the other (Mittal and Lassar, 1996). A provider can be accommodating and tend to a customer's needs, for example by small talk during an examination to calm a scared patient, without doing anything to change the provided service nor changing the way the examination is delivered, and vice versa (ibid). The characteristics of services, such as often being simultaneously produced and consumed and a high level of interpersonal contact (e.g. Lovelock and Gummesson, 2004), advocate simultaneous application of customisation and personalisation as there is a possibility to adapt both the service itself and the personal interactions between provider and patient (De Blok et al., 2013). 


\section{Methodology}

This chapter presents the methodology used in this thesis. It starts with the research design. Next follows, research methods, data analysis, and methodological considerations. The aim of the chapter is to explain and motivate the methodological choices made.

\subsection{Research design}

This thesis is a compilation based on three papers; where the thesis offers its own contribution. All papers are based on the same empirical context, CCPs implemented in Sweden during 2015 to 2020. However, as seen in Table III, their topics differ and spans from the application of care pathways in a coordination centre, through CCP coordinators, to the effect of CCPs on waiting times. An overview of the appended papers can be found in Chapter 5. In the analysis of this thesis, the data collected for the papers are related to the theoretical framework specifically formulated for the thesis.

Table III: Appended papers and their contribution to the thesis

\begin{tabular}{|c|c|c|c|}
\hline Paper no. & 1 & 2 & 3 \\
\hline Title & $\begin{array}{l}\text { The management of cancer } \\
\text { care pathways in a } \\
\text { coordination centre }\end{array}$ & $\begin{array}{l}\text { Care coordinators as a means to } \\
\text { improve continuity and quality } \\
\text { of patient care }\end{array}$ & $\begin{array}{l}\text { The effects of cancer care } \\
\text { pathways on waiting times }\end{array}$ \\
\hline $\begin{array}{r}\text { Topic in } \\
\text { CCPs }\end{array}$ & $\begin{array}{l}\text { Standardised and } \\
\text { customised care pathways }\end{array}$ & Coordination and coordinators & $\begin{array}{l}\text { Waiting times and } \\
\text { crowding-out effects }\end{array}$ \\
\hline Approach & Qualitative & $\begin{array}{l}\text { Quantitative } \\
\text { Qualitative }\end{array}$ & Qualitative \\
\hline Method(s) & $\begin{array}{l}\text { Case study: interviews, } \\
\text { document study (1), } \\
\text { observation studies }\end{array}$ & Survey (response rate $72 \%$ ) & Document study (2) \\
\hline Contribution & $\begin{array}{l}\text { - Different forms of care } \\
\text { pathways } \\
\text { - Role of coordination in } \\
\text { care pathways } \\
\text { - Role of multidisciplinary } \\
\text { work }\end{array}$ & $\begin{array}{l}\text { - Coordinator roles } \\
\text { - Role of coordination in care } \\
\text { pathways }\end{array}$ & $\begin{array}{l}\text { - Effects of CCPs such } \\
\text { as accessibility, } \\
\text { timeliness, and } \\
\text { equitability }\end{array}$ \\
\hline
\end{tabular}

The research design in this thesis has been influenced by the fact that this thesis is a compilation of papers developed from three independent research projects. The papers were written in the order 3, 2, 1 as listed in Table III and were all written before the main thesis work started. No literature reviews were conducted for the papers, so the author considered it necessary to develop a new and more extensive frame of reference for the thesis. The empirical data were collected by the author of this thesis together with co-researchers in the individual research projects, during 2016-2017, see next section. Because all the research projects linked to the papers had finished when the main thesis work started, the author did not have the opportunity to collect additional data.

Instead, the author went back to the raw data to explore what brought these topics together and understand if and, in that case, how they complement each other. This explorative approach is useful to gain a better understanding of an existing problem that is not clearly defined, by allowing new insights to steer the direction of the research (Eisenhardt, 1989). The aim has been to try to see past the context in which the projects have been conducted and to apply a holistic perspective on how the topics from the papers influence care delivery. The two main constructs, care pathways and patients with complex care needs were derived from CCPs (an improvement programme to implement care pathways), and cancer patients (who are associated with complex care needs). 
After the author decided to focus on care pathways and patients with complex care needs an abductive approach was applied, using a mix of qualitative and quantitative research methods. Abduction is a research approach where the author takes the starting point in empirical observations and goes back and forth between the empirical and theoretical worlds to develop an understanding of a phenomenon (Kovács and Spens, 2005). Abductive reasoning is often used to find plausible reasons for a phenomenon when data are fragmented or lack completeness; however, it is often not enough to completely verify them (Merriam, 1998). The raw data from the projects were more extensive than that presented in the papers, so these additional data were used as a complement to the findings in the papers. The findings and analyses presented in the papers constituted the basis for formulating the research questions and making the first draft of the theoretical framework. By returning to the empirical data, new surprising 'facts' have emerged for which explanations have been searched for in the literature and then anchored in the theoretical framework. The framework has then evolved over several iterations between the empirical data and the literature (Dubois and Gadde, 2002). New analyses were conducted on the raw data as the theoretical framework evolved. This iterative process generated the practices studied in this thesis.

\subsection{Research methods}

To achieve the purpose of this thesis, four main research methods were used: literature review, case study, survey, and document study. The survey mainly provide data for research question one and the document study for research question two. The literature review and case study support both research questions see Table IV.

Table IV: The research methodology related to the research questions.

\begin{tabular}{l|cccc}
\multicolumn{1}{c}{ Research questions } & $\begin{array}{c}\text { Literature } \\
\text { review }\end{array}$ & $\begin{array}{c}\text { Case } \\
\text { study }\end{array}$ & Survey & $\begin{array}{c}\text { Document } \\
\text { study }\end{array}$ \\
\hline $\begin{array}{l}\text { RQ1: How can care pathways be managed using the } \\
\text { practices coordination, standardisation, }\end{array}$ & $\mathbf{X}$ & $\mathbf{X}$ & $\mathbf{X}$ & \\
customisation, and personalisation for patients with \\
$\begin{array}{l}\text { complex care needs? } \\
\text { RQ2: How can these practices influence quality of } \\
\text { care? }\end{array}$
\end{tabular}

Data collection started in 2016 with a case study for the Master's thesis conducted by the author of this thesis (Smeds, 2016). Three main data collection methods, observational studies, document study, and interviews, were used to acquire an understanding of implementing CCPs in a Swedish region. The second part of the data collection was a document study on the effects of CCPs on waiting times. In the third part, a survey was conducted on coordinators in CCPs. The main thesis work was conducted in 2018-2019. Other research projects, not included in the thesis, were conducted during 2017. Figure 2 presents a timeline for data collection and analysis in this thesis. In the following sections, the research methods are briefly presented. A complete description of the research methods can be found in the appended papers. 


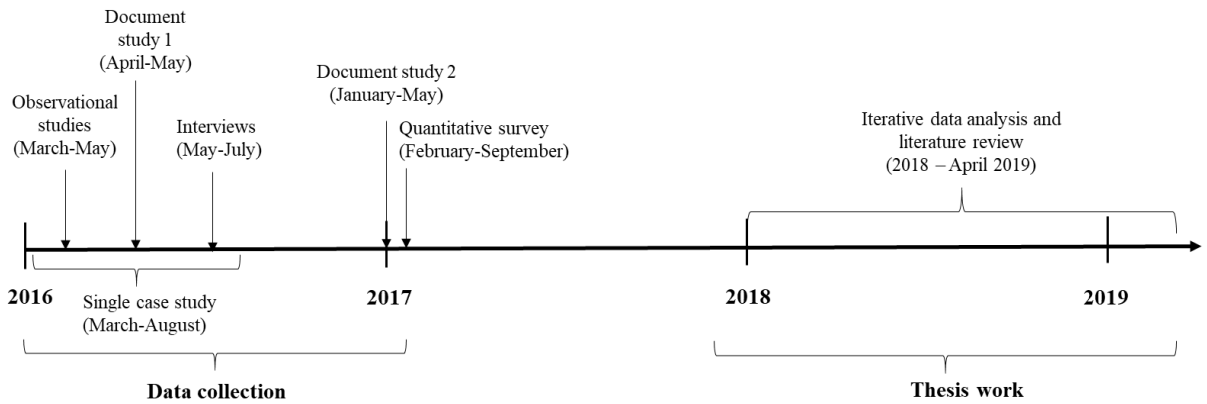

Figure 2: Timeline for data collection and thesis work.

\subsubsection{Case study}

The case study was conducted in one Swedish region at the start of implementing the CCP. The reason for selecting the studied region was twofold: convenience (Yin, 2009) as it was located close to the researchers and it received regional funding. However, it emerged that the case also included a unique solution (ibid), a new organisational unit responsible for needs assessment and coordination. As not much was known about CCPs, a case study was designed to gain a first understanding of the content and practical operationalisation of CCPs. Case studies are generally used to describe and understand real life settings where the phenomenon cannot be separated from the context and to explain causal links in the data (Yin, 2009). This was the first study conducted on CCPs and it provided a great opportunity to explore CCPs and search for interesting phenomena to study further.

Three qualitative data collection methods were used: document studies, interviews, and observation studies. The multiple data sources were used for triangulation to increase the reliability and validity of the study (Merriam, 1998, Patton, 2002). Triangulation was conducted by comparing answers from the interviews with findings from the document analysis and observations.

Three interesting themes arose from the case study. The first was the care pathways applied by the organisational unit, also called the coordination centre, which is the theme for the first paper. The second was the various coordination needs in the healthcare system, which is the theme for the second paper. Finally, the topic on waiting times, and in particular questions regarding longer waiting times for other patient groups, which is a national concern, and which is presented in the third paper.

\section{Document study (1)}

The document study was based on internal strategic documents on CCPs written by the CCP-project leaders in the region and the regional cancer centre during 2015-16 (the document study was extended to 2018 during the data analysis for the thesis). The documents focused on implementation of CCPs, development of a new organisational unit, and other related improvement projects in cancer care. The purpose of this document study was to develop an understanding of how the region had started and was continuously planning to operationalise the CCPs. Notes were compiled from the study to use as a basis for interview questions.

\section{Observation studies}

Non-participative observations were conducted at which the authors were merely observers (Patton, 2002) both in meetings and by shadowing project leaders and coordinators. The first observation was with the coordinators to gain insight into their work contacting patients, for example for needs assessment and appointment scheduling. The author also followed the project leaders to meetings with their project group and multidisciplinary collaboration meetings. During the observation, field notes were collected to be used as a basis for interview questions. Three multidisciplinary conferences were 
also observed. The purpose was primarily to acquire a picture of the complexity of diagnostics and treatment of cancer patients. In addition, it provided an opportunity to gain insight into how the multidisciplinary conferences are conducted, for example the interaction between different roles, decision making, and discussion climate. Participation at various meetings was used both to understand more about multidisciplinary work and to find new issues and subjects to study further.

\section{Interviews}

Interviews were held with the two project leaders, three physicians, five nurses, two coordinators, two care unit managers, and two general practitioners. The project leaders were interviewed twice, once after conducting the other interviews and once again a few weeks later as follow-up. Participants were selected by convenience and using purposeful selection (Miles and Huberman, 1994) with the desire to include participants from different parts and levels of the healthcare system. The first step in identifying respondents was to map a few patient processes in order to find providers working with CCPs. Interview requests went out to all of these providers. Because only a few replied, convenience had to be applied when selecting respondents. Convenience was based on who worked in a particular care unit during that time (it was the summer holidays), and who replied to the interview request. The second step was to ask the CCP project leaders for suggestions of who to include.

The interview questions were based on knowledge gained in the document study, observation studies and a theoretical framework on implementation science. The interviews were based on a predetermined list of open-ended questions (Kvale, 1996), lasted between 45 minutes to two hours, were recorded, and afterwards transcribed by the author. The interviews provided knowledge on how CCPs had influenced the day-to-day work, and the providers' perception of the implementation and outcomes for patients.

\subsubsection{Document study (2)}

The document study was a direct result of the previously described case study. During the case study, a research gap on crowding-out effects became evident. It was perceived as a problem in the region studied, so the question arose as to whether this was a broader phenomenon that was also experienced in other regions and, if so, how was it discussed in other regions. This information could be found in a series of mandatory implementation reports, available online on the Regional Cancer Centre in Cooperation (RCCC) website, written by the regions on request from the National Board of Health and Welfare to follow up the regional implementations. Since the reports contained information about the topic of interest in all regions, a document study was chosen to gain more information. A document study can be used to systematically analyse internal or external documents (Bowen, 2009). Other types of research methods such as interviews or a survey could have been used to gather the same information. However, due to the nature of the documents, which had been reviewed by the National Board of Health and Welfare and written over a few years by the project leaders, and the convenience of availability, this methodology was seen as a good choice. A total of 105 documents, in the form of CCP implementation reports from all 21 regions published twice a year between the years 2015-2017, were reviewed.

\subsubsection{Survey}

Coordinators were introduced nationally together with the CCPs. The author's interest in coordinators arose during the case study, and the author was given the opportunity, together with the main supervisor, to conduct a nationwide survey on behalf of the National Board of Health and Welfare. The knowledge on coordinators from the case study was used to form the hypothesis that there would be a national difference in the coordinator's role. A survey methodology was selected to gain a deeper understanding of the coordinator's role and work in relation to CCPs and to cover this large target population scattered across the country. The respondents were all coordinators actively working in secondary care in 2017. $\mathrm{CCP}$ project leaders were consulted to assist in finding respondents in each region. This ensured that as many relevant respondents as possible were targeted and that they were actively working with CCPs. 
The questions were based on previous research on coordinators both nationally (NBHW, 2015a, NBHW, 2016) and internationally (e.g. Axelsen et al., 2014, Bayard et al., 1997, Cancer Institute NSW, 2011, Freijser et al., 2015, Lie et al., 2018a, Lie et al., 2018b). A pilot test was performed with coordinators and providers with similar roles to test the participants' understanding and interpretation of the questions, and to ensure that the content was relevant to the respondents.

Data were collected through a web-based survey which is a fast, easily accessible and inexpensive way of reaching a large number of respondents (Jansen and Corley, 2007). In total, 496 care coordinators were asked to participate in the survey, and the result was a response rate of $72 \%$.

\subsubsection{Literature review and formation of theoretical framework}

A literature review (Bryman, 2004) was conducted as part of the thesis to gain more knowledge on topics related to care pathways. It was particularly important in building the theoretical framework and the framework for quality of care. Articles, reports and books were studied based on key word searches in Scopus, Web of Science, and Google Scholar. Scopus and Web of Science were used for more systematic searches because they cover both medical and management research areas, while Google Scholar was used for additional sporadic searches. Peer-reviewed sources were mostly used; however, other sources such as grey literature and reports were read to extend the knowledge base. In addition, snowball sampling was used in the articles which seemed particularly relevant in order to find additional articles of interest. The literature review and theoretical framework evolved through several iterations going back and forth between the empirical data and literature.

The first draft of the literature review was based on the main constructs care pathways and patients with complex needs and the frameworks from the included papers in this thesis. Theory on standardised and customised care pathways had been briefly presented in Paper 1, and were thoroughly studied in the literature review. Three pathway frameworks were selected, and their characteristics were compiled into Table I and Table II. The frameworks represent different perspectives relevant for managing healthcare: medical (provider) (Bohmer, 2009), quality management thinking (Lillrank, 2003), and value theory (Stabell and Fjeldstad, 1998). The practice personalisation arose from literature on customisation and, due to the importance of communication for patients with complex care needs, this topic was also added to the theoretical framework. What was striking when studying the standardised and customised pathways, was the lack of coordination and patient focus. Even though all frameworks describe chains of activities, which usually involve a number of providers and handovers between providers, only one of the three frameworks, Stabell and Fjeldstad (1998), mentions the need for coordination to handle interdependencies between activities. This is a bit surprising since it is the only framework not particularly aimed at improving care for patients but rather for how firms can improve their value proposition to its customers. It is noteworthy that in a time when patient centeredness and coordination is widely discussed internationally, it is not included as a central part of care pathways. The empirical material also highlighted the importance of coordination in care pathways. The theoretical framework was therefore extended to include coordination.

The literature review also studied literature on quality of care which was used to develop the framework for evaluating the influence of the practices on quality of care in care pathways (see Figure 1). The structure-process-outcome model (Donabedian, 1966) was chosen as the basis for the framework as it matched the author's view that care pathways and coordinators were implemented at a structure level and practices were used at process level. A number of frameworks on quality of care dimensions were then studied. The dimensions chosen for study were those considered important for patients with complex care needs, and which matched the aim for CCPs. The developed framework is highly influenced by a paper on quality of care (Campbell et al., 2000) which also used the structure-processoutcome model to assess quality of care for both individual patients and society. Alike the study by 
Campbell et al. (2000), the quality dimensions accessible and equitable along with timely care and patient-centredness was used to evaluating the practices influence on quality of care.

\subsection{Data analysis}

Data analysis was conducted in two parts. The first part was the data analyses conducted for the individual papers. Data analysis in the case study was based on a theoretical framework on care pathways. The analysis focused on mapping and illustrating the work process in, and the perceived effects of, the coordination centre. The interviews with personnel working in the coordination centre, coordinators and project leaders, and the document study were the basis for outlining the work process. The effects were derived from a pattern analysis based on all interviews.

The analysis in the document study was a combination of a systematic word search and theme categorisation (Bryman, 2001). Words and themes was derived from previous reports that discussed these topics (NBHW, 2015a, NBHW, 2016), such as crowding-out, inclusion, waiting time, lead time, accessibility and equitability. All reports were then searched using the key words, and citations referring to a theme were compiled in an Excel sheet. The compilation showed which regions mentioned a certain theme and counted how many times a topic was mentioned.

Data analysis in the survey was conducted both quantitatively and qualitatively. Quantitative analyses were performed in SPSS using descriptive statistics to calculate means and percentages, and hypothesis testing was performed using ANOVA and chi-two tests. Qualitative analysis was conducted on comments and free text answers. It was based on qualitative content analysis (Patton, 2002) where the responses were categorised and summarised based on topic. The comments were then summarised and counted in each category. A detailed description of the data analysis for the papers can be found in the respective papers.

The second part of the data analysis conducted for the thesis was based on clustering and finding patterns in the raw data from the interviews and qualitative responses from the survey (Miles and Huberman, 1994). The analysis was conducted stepwise, first for research questions 1 and then 2 . As previously described, the theoretical framework emerged through several iterations and subsequent analysis. The empirical material, such as interview transcriptions and qualitative answers from the survey, was read through several times and coded based on the emerging themes such as standardised and customised care pathway, coordination, continuity, and so forth. Illustrative citations from the various topics were selected and compiled into an Excel sheet. The data were then clustered based on topic and analysed according to the theoretical framework. Along with the emerging theoretical framework, some of the codes and themes also changed. This was the case when personalisation was separated from customisation, and continuity was highlighted in coordination.

\subsection{Methodological considerations}

To ensure that the collected data is useful, the methodology must provide reliable and valid results. Reliability relates to the trustworthiness of the data and that the same results would be achieved if the study was repeated (Miles and Huberman, 1994). Ensuring reliability can be problematic in qualitative research due to the fact that both the surrounding society and people are constantly changing (Merriam, 1994). A limitation is the selection of the interview respondents based on convenience (Miles and Huberman, 1994). It is therefore difficult to know definitely that the result actually reflects reality and that the result would be the same if other respondents had been chosen. A reactive strategy has therefore been to have several respondents within the same profession, but from various specialisations, in order to ensure that their perception is similar.

Three types of validity can be used to ensure valid results: construct, internal, and external. The first, construct validity, refers to the extent to which the data cover all relevant aspects of a theme, and this can be achieved by using multiple data collection methods and creating a chain of evidence (Miles and 
Huberman, 1994). The document study has a few limitations in this regard. Firstly, the documents may be incomplete. Because they have been reviewed by the National Board of Health and Welfare, there is a possibility that the regions may have omitted some information from the reports to avoid criticism from the National Board of Health and Welfare. In particular, questions about accessibility and timeliness, which are important goals for the CCPs, can be a sensitive topic. Secondly, the regions have chosen to answer the questions in different ways. In some cases, the project leaders have written the whole report alone while, in others, providers from different parts of CCPs have been involved in the writing. Some reports contain a more general discussion on these topics while others discuss at the individual CCP level. In addition, the questions have been interpreted differently making it slightly difficult to compare some of the answers. This was the reason the counting analysis method was used, because it did not make comparisons between regions but only determined whether a topic was mentioned or not. Despite these limitations, the document study was a good first step to map the effects of timeliness and equitability. Moreover, the document study was supplemented with discussions with the National Board of Health and Welfare and regional CCP project leaders to validate the results.

Internal validity refers to the extent to which the methods really can capture the themes to be studied (Miles and Huberman, 1994). In the case study, observations and the document study were used for triangulation. In addition, the interview questions and data analysis were discussed with a researcher studying implementation science to ensure validity in terms of capturing the right information (Patton, 2002). Discussing data collection and analysis with others has also been important throughout the data collection in this thesis. Involved actors, such as CCP project leaders (case study, quantitative survey and document study), National Board of Health and Welfare (survey) and other researchers (case study and document study) have been asked to comment on research design, interview guides and preliminary analysis. Based on these discussions, changes were made to simplify some of the questions for the interviews. The use of a structured interview guide facilitated data-quality checks of whether the respondents' answers agreed with the general perceptions of the other respondents.

External validity refers to the extent to which findings can be generalized and transferred to other contexts. This thesis is based on one empirical context, CCPs. The case study is based on data from one region, and the quantitative survey and document study on nationwide data. The data can thereby both provide a broad understanding of the phenomenon and, in one case, the possibility to examine in-depth. This provides a more holistic understanding than if only one in-depth case was used. Nonetheless, the inclusion of more cases could have strengthened the validity, given a deeper understanding of the phenomenon, and increased the generalisability for the empirical object under study (Yin, 2009). This thesis proposes that findings from CCPs on cancer patients can be generalised to patients with complex care needs. This hypothesis is strengthened by the literature which highlights similar needs for these patient groups. Notwithstanding, including more cases of patients with complex care needs could have strengthened the generalisability of the results. 


\section{Overview of appended papers}

This chapter provides an overview and summaries of the appended papers in this thesis. Three papers are appended, each with its own contribution. The methodology of the individual papers can be found in the articles and in the Chapter on Methodology in this thesis. The focus in this chapter is to present the results of the papers which is part of the analysis presented in the next chapter.

\subsection{Paper I: The management of cancer care pathways in a coordination centre}

Providing diagnostics for patients with complex care needs, such as cancer patients, is a great challenge for the healthcare system due to patients' differentiated service requirements generated by their needs, prerequisites, and requests. There are several theoretical frameworks on standardised and customised process models which are suggested as one way to manage processes with variable input (e.g. Bohmer, 2009, Lillrank, 2003). The aim of the paper is to study how standardised and customised pathways can be used in healthcare to manage care for cancer patients. The paper is based on a case study in a coordination centre in Sweden.

The coordination centre, The Unit for Coordinated Cancer Diagnostics, acts as a gatekeeper for referrals between primary and secondary care. As gatekeepers, their role is to ensure the quality of incoming referrals and that the patient's symptoms match the alarm symptoms in a CCP-guideline. This increases accessibility to cancer care because general practitioners only have to refer the patient to one referral recipient. The next two steps are needs assessment and triage, and pathway selection. Horizontal coordinators conducted needs assessment and triage to assess urgency as well as physical, psychosocial, supportive, and practical needs, in order to plan the continuous care pathway. Pathway selection was thereafter performed to decide whether a patient required a standardised or a customised pathway.

By assessing not only the symptoms but also the needs, sick patients receive holistic care. This way, resources can be allocated to patients with the highest support and medical needs. Usually, patients with clear symptoms and a low need for support are assigned to a standardised pathway, while those with ambiguous symptoms and comorbidity are assigned to a customised pathway. Working with care pathways is considered to have improved the initial part of the diagnostics process relating to information collection and acquisition of a holistic view of the patient group. The findings also showed that care delivery in the standardised pathway was similar to 'traditional' care delivery but in addition followed CCP guidelines, whereas a more multidisciplinary approach was applied in the customised pathway.

This paper contributes to the thesis with knowledge on how different types of care pathways, such as standardised and customised pathways, can be used to care for cancer patients. It also highlighted the importance of holistic needs assessment due to the differentiated service requirements of the patient group. Finally, it points to the need for horizontal coordination to provide equitable assessments and centre providers around the patients.

\subsection{Paper II: Care coordinators as a means to improve continuity and quality of patient care}

Patient centredness, coordination, and continuity are considered to be important elements of healthcare. However, previous research shows that working with these elements has proven to pose a great challenge to parts of the healthcare system. In Sweden, a new role, care coordinator, was developed and implemented nationwide along with the introduction of CCPs. The systematic introduction of coordinators in cancer care is one of the first of its kind (in Sweden) and provides a good opportunity to gain more knowledge on the coordinator's role in healthcare. The aim of this paper was to explore the coordinators' roles, challenges, and contributions to healthcare. 
The results show that there is no 'one size fits all' solution to appointing coordinators. The nationally stated purpose of the coordinators was to follow up waiting times and to ensure coordination and continuity. However the role was appointed and developed individually by each region, leading to a wide variety of coordinators with different roles and characteristics. Three roles were identified: horizontal, unit, and patient coordinators. The unit coordinator has an administrative nature and an internal coordination focus such as booking appointments and registering and reporting lead times. The main focus of the patient coordinator is to act as a contact person, to coordinate the pathway with the patient and to continuously assess and advocate their needs. The horizontal coordinator works at the system level to assess patients' needs before following a CCP, and has an overall responsibility to coordinate and monitor the work with the CCPs. One main challenge comes from the multifaceted nature of the role resulting in coordinators performing tasks they are not trained to do. The patient coordinators express that they think more time should be spent with patients and less on administrative tasks whereas unit coordinators express difficulties in performing patient-related tasks due to a lack of knowledge of medical or psychosocial care. Another challenge concerns prioritising patients. Many coordinators have to make daily prioritisations to ensure that patients with the highest care need gets first priority, which is not always easy in a constrained system. The coordinators perceive their work as important for making the diagnostic process more effective and shortening waiting times. In addition, the role contributes to coordination and continuity in the care process, for example by improving cooperation between healthcare providers.

This paper contributes with knowledge about three coordinator roles working with CCPs. The result also shows that coordinators fulfil different needs in the healthcare system and that they are important for maintaining coordination and continuity at different levels in the healthcare system.

\subsection{Paper III: The effects of cancer care pathways on waiting times}

Crowding-out effects have been a hot topic in the Swedish healthcare system for a long time. The debate blossomed along with the implementation of CCPs when prioritisation of the cancer patients was argued to lead to longer waiting times for other patient groups (e.g. Wilkens et al., 2016). Even though the understanding of crowding-out and its actual effects are not clearly established, 'everyone' seems to have an opinion on its meaning and presence in the healthcare system. The aim of this paper was to elucidate and define crowding-out effects associated with CCP implementation.

Crowding-out effects have been defined by the National Board of Health and Welfare as occurring when a patient with a higher priority has to wait in favour of a patient with a lower priority (NBHW, 2016). Three effects were identified under the umbrella term crowding-out: inclusion, push-out and exclusion effects. The inclusion effect occurs when patients, who would previously have had problems accessing cancer diagnostics due to ambiguous symptoms, are now included because of the predetermined inclusion criteria. The push-out effect is the negative effect when patients in urgent need of care have to wait in favour of patients with a lesser need. Finally, the exclusion effect occurs when patients who match the description for a CCP are denied access to follow the fast track but instead follow a traditional care pathway. The result has thereby revealed that crowding-out includes not only negative but also positive effects. The perceived main contributing factors to increased waiting times were increased numbers of cancer patients going through cancer diagnostics, lack of capacity, and giving CCP patients priority for appointments.

This paper contributes with knowledge on regional CCP project leaders' perception of timeliness and equitability of care in CCPs. In addition, this paper elucidates the three effects inclusion, exclusion and push-out. These effects provide important insight into what crowding out really means, and it is important to consider these when discussing the outcomes of CCP implementation. The paper also makes a first attempt to delineate potential reasons for the occurrence of these effects. 


\section{Analysis and discussion}

This chapter elaborates on the theoretical framework and the empirical findings to answer the research questions and fulfil the purpose. The first part elaborates on care pathways. Thereafter follows a discussion on the practices coordination, standardisation, customisation and personalisation, and their operationalisation through care pathways and coordinators. The chapter ends with a discussion about the influence of these practices on quality of care. In this chapter, the practices and other aspects related to care pathways are discussed in regard to CCPs which form the empirical context in this thesis.

\subsection{Understanding care pathways in the context of CCPs}

The first part of this chapter presents the analysis and discussion of the first research question: how can care pathways be managed using the practices coordination, standardisation, customisation and personalisation, and be applied for patients with complex care needs? To answer this question, there is firstly a need to elaborate on the use of care pathways. This section explains how care pathways can be understood in the context of CCPs. As previously described, CCPs is a national improvement programme aimed at reducing waiting times, regional differences and fragmentation in cancer care. Important elements included in CCPs are CCP-guidelines including alarm symptoms for individual cancer diagnoses, maximum waiting time limits, and coordinators.

In the literature, care pathways are described as structured plans for organising and making decisions about patient care processes, developed in collaboration by providers from different specialties, to provide best practice care (Zander, 2002) for a well-defined group of patients during a well-defined time period (Vanhaecht et al., 2007). CCPs fit this description quite well since CCPs are developed by national multidisciplinary expert groups and focus on outlining care delivery for individual cancer diagnoses during the diagnostic process from first symptom until start of first treatment. An example from the case study of a CCP for a well-defined group of patients is those with suspected breast cancer. Clear alarm symptoms such as a lump in the breast or armpit or changed shape of the breast indicate a cancer disease and the disease can be confirmed by examinations of the affected area.

Paper 1, however, shows that CCPs can also be used for patient groups which are not typically seen as well-defined, namely patients with serious unspecific symptoms (SUS) and cancer of unknown primary tumour (CUP). As the names imply, these are pathways for patients where cancer diagnosis is suspected but due to uncertainty in the origin of symptoms, these patients cannot be referred to a diseasespecific pathway because there is no association with a specific cancer diagnosis. The CCPs for SUS and CUP specify ambiguous or unclear symptoms that may indicate cancer such as extreme weight loss or lengthy headaches, or advanced cancer without known origin, and how to diagnose to confirm or dismiss a cancer disease. Patients entering one of these CCPs can thus have a variety of symptoms and can all be diagnosed within the same care pathway. This shows that it is possible to develop care pathways for more diversified groups as well as well-defined groups.

\subsubsection{Four aggregation levels of CCPs}

The four aggregation levels outlined by Vanhaecht et al. (2010) for care pathways correspond quite well with the way in which CCPs were introduced in the healthcare system. National expert groups with providers from different specialties and professions developed CCP-guidelines, model pathways, for 31 cancer diagnoses. Implementing CCP-guidelines is however only one element of the holistic strategy aimed at improving cancer care. Other elements such as systematic measurements of lead times, following up waiting times, introduction of coordinators to enhance coordination in the CCPs and introduction of pre-schedule appointments are being simultaneously implemented. The holistic strategy is perceived to contribute to the development of a common language, to a national consensus on how to deliver cancer care, and to mutual learning between the regions (NBHW, 2017). 
The model pathways were implemented at regional level where they were translated and adapted at hospital and/or unit level to conform to local settings, organisational structures, and approaches for delivering care, to form the operational pathway. Most regions could use the existing structures for managing the CCPs. The exceptions were CUP and SUS which were new. This resulted in the development of several local diagnostic centres (e.g. Regional Cancer Centre in South of Sweden, 2019) where multidisciplinary teams from various specialities work together to perform and interpret tests and examinations to identify underlying cancer diseases in patients following CUP and SUS (ibid). Previous studies advocate multidisciplinary teamwork to promote timely care and improved care outcomes when dealing with uncertainties in diagnostics (Gittell et al., 2000, Vanhaecht, 2007). Besides developing diagnostic centres and undertaking necessary adaptions in individual care units, realisation of the CCPs also resulted in changed responsibility for care delivery with care for some diseases being centralised to single hospitals or regions, and reorganisations were undertaken to decrease geographical distances between providers involved in the same pathway.

The assigned pathway is the pathway that is planned together with patients in the early stages of the diagnostic process. A care pathway which adheres to the CCP guidelines in the model pathway can be described as standardised while a care pathway which needs to be adapted to the patient's needs becomes customised. The goal with the pathways is for the providers to follow the sequence of the care activities stipulated in the model pathway as closely as possible during the operational care delivery process. The final care pathway can be followed up in the actual pathway. The actual pathway is, however, not actively used to follow-up care processes but can, if necessary, be backtracked in the patient journal. The four pathway levels are presented in Figure 3. The next section explains the need and operationalisation of the practice coordination in care pathways.

Figure 3: Four levels of care pathways in CCPs.

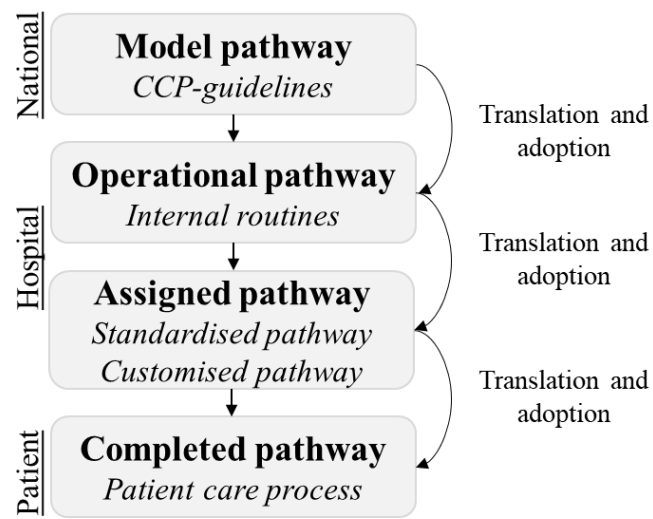

\subsubsection{Care pathways and coordinators as coordination mechanisms}

Previous chapters have highlighted the importance of coordinating care between providers in the care pathways and between patients and providers (Malone and Crowston, 1994, McDonald et al., 2007). Standardisation is an important and well-used coordination mechanism (Mintzberg, 1980, Mintzberg and Glouberman, 2001, Galbraith, 1974); hence, a care pathway itself can be seen as a coordination mechanism. One of the care pathway's roles is to make work tasks and responsibilities clear for providers. It is in the translation from model to operational pathways that care gaps and transitions between providers become apparent. A regional project leader describes the care pathway as an interface guideline that defines dedicated criteria to be fulfilled by each provider, when to hand over a patient, and to whom. One example from Paper 1 is the alarm symptoms included in the CCP guidelines. The 
alarm symptoms can be seen as a coordination mechanism between primary and secondary care stipulating which patients should be referred to secondary care. This can be seen as a strategy to reduce the need for interaction between actors as described by Hoffer Gittell (2002).

Even so, neither care pathways nor alarm symptoms enable coordination on their own, but require compliance by providers and, perhaps, additional coordination mechanisms to be successful. Paper 1 described the use of a standardised referral template necessitating the general practitioner to fill in any alarm symptoms that had been identified. This kind of coordination mechanism can be used to further enhance compliance with the alarm symptoms.

In CCPs, coordinators are seen as a vital coordination mechanism both within and between care pathways, and with the patient (NBHW, 2017). The next section analyses coordinators' roles in managing care for patients with complex care needs.

\section{Three coordinator roles: patient, unit and horizontal coordinator}

The recently developed national work statement for coordinators states that a coordinator is an administrative support function that should assist the healthcare system in ensuring that the maximum waiting times are met (RCC, 2017). Paper 2 describes three different coordinator roles in CCPs: patient coordinator, unit or pathway coordinators (hereinafter unit coordinator), and horizontal coordinator see Table V. Similar coordinator roles have been distinguished by other scholars (e.g. Freijser et al., 2015). Coordinators are typically appointed to specifically work with coordination by facilitating communication between two interdependent actors such as units, departments or teams (Galbraith, 1974).

Table V: Characteristics of the three coordinator roles

\begin{tabular}{|c|c|c|c|}
\hline Characteristics & Horizontal coordinator & $\begin{array}{c}\text { Unit or pathway } \\
\text { coordinator }\end{array}$ & Patient coordinator \\
\hline $\begin{array}{r}\text { Coordination } \\
\text { focus }\end{array}$ & Holistic and patient & Provider and patient & Patient \\
\hline $\begin{array}{r}\text { Level of } \\
\text { appointment }\end{array}$ & $\begin{array}{l}\text { Hospital/region } \\
\text { (centralised) }\end{array}$ & $\begin{array}{l}\text { Care unit/pathway (s) } \\
\text { (decentralised) }\end{array}$ & $\begin{array}{l}\text { Care unit/pathway (s) } \\
\text { (decentralised) }\end{array}$ \\
\hline $\begin{array}{r}\text { Type of } \\
\text { continuity }\end{array}$ & $\begin{array}{l}\text { Management } \\
\text { (Informational) }\end{array}$ & Informational & $\begin{array}{l}\text { Relational } \\
\text { (Informational) }\end{array}$ \\
\hline $\begin{array}{r}\text { Role towards } \\
\text { patient }\end{array}$ & $\begin{array}{l}\text { - Initial needs assessment } \\
\text { - Initial urgency } \\
\text { assessment } \\
\text { - Assign standardised or } \\
\text { customised pathway } \\
\text { - Initial information } \\
\text { sharing and } \\
\text { communication }\end{array}$ & $\begin{array}{l}\text { - Key contact person for } \\
\text { administrative needs } \\
\text { - Follow up on waiting } \\
\text { times and compliance to } \\
\text { standardised or } \\
\text { customised pathway } \\
\text { - Provide contact } \\
\text { information to new care } \\
\text { providers }\end{array}$ & $\begin{array}{l}\text { - Key contact person for } \\
\text { emotional support and } \\
\text { medical needs } \\
\text { - Continuous needs } \\
\text { assessment } \\
\text { - Continuous adaptation and } \\
\text { customisation of care } \\
\text { pathway } \\
\text { - Continuous information } \\
\text { sharing and communication }\end{array}$ \\
\hline $\begin{array}{r}\text { Role towards } \\
\text { providers }\end{array}$ & $\begin{array}{l}\text { - Interfunctional and } \\
\text { interpersonal transferral } \\
\text { of patient information } \\
\text { - Uphold effective } \\
\text { communication and } \\
\text { cooperation in CCPs }\end{array}$ & $\begin{array}{l}\text { - Interfunctional and } \\
\text { interpersonal transferral } \\
\text { of patient information }\end{array}$ & $\begin{array}{l}\text { - Patients advocate at } \\
\text { multidisciplinary } \\
\text { conference } \\
\text { - Uphold effective } \\
\text { communication and } \\
\text { cooperation in care pathway } \\
\text { - Interfunctional and } \\
\text { interpersonal transferral of } \\
\text { patient information }\end{array}$ \\
\hline
\end{tabular}


Lack of clear guidance in organising the roles in the early stages of implementing CCPs required each region to design the roles as it suited them. In line with previous research on the importance of providing patients with a contact person (e.g. Nazareth et al., 2008, Walsh et al., 2011, Shaw et al., 2018), all three roles share the remit of being a contact person for both patients and providers at some point in the care pathway, but fulfil different kinds of coordination purposes. Horizontal coordinators coordinate primarily at hospital or regional level (macro level), unit coordinators at unit or CCP level (meso level), and patient coordinators at patient level (micro level).

Usually, in cases of care provision for patients with complex needs, no one person has the overall responsibility for managing all the patient's needs. It is typical in a professional organisation for each unit to only take responsibility for their part of the process, with no one taking holistic responsibility (Mintzberg, 1980). Paper 1 reveals that this is where the role of the horizontal coordinator comes in. Examples of working with horizontal coordinators in CCPs can be found in two regions (RJH, 2018, RÖ, 2016).

The horizontal coordinators role is twofold. The first role is to act as a process owner (Bergman and Klefsjö, 2010) for CCPs. The role can be likened with an integrator role which are disconnected from other actors and exercise expert power as a result of their exclusive access to information and knowledge that can be used to make decisions and coordinate between actors (Galbraith, 1974). Paper 1 showed that the horizontal coordinators centralised position offered a holistic view of the CCPs with enabled communication and cooperation between providers in the healthcare system. Examples described by a horizontal coordinator included visiting primary care centres to inform and discuss the use of alarm symptoms, and receiving permission from care units to book appointments directly in their booking systems. In cases where customisation of a care pathway is needed, the horizontal coordinator also has the opportunity to consult specialists during a multidisciplinary meeting to ensure that all needs are appropriately safeguarded. The position also provides a holistic view of the patient groups following CCPs; enables prognosis prediction for incoming patients; and the investigation of bottlenecks in the CCPs.

The second role of the horizontal coordinator is to act as a gatekeeper for incoming referrals from primary care and to conduct a preliminary needs assessment. The horizontal coordinator matches the alarm symptoms with a CCP, assesses the urgency, and plans a more or less standardised or customised pathway accordingly in agreement with the patient. To establish informational continuity (Haggerty et al., 2003) the coordinator ensures that all information is transferred when referring to the diagnosisspecific unit. A horizontal coordinator expresses "What I talk to the patient about and write about the patient [in the patient journal] should be a basis for the next conversation and contribute to increased quality. The next person must not need to ask the same thing”. Doing the assessments and overall planning early in the process enables patients to receive appropriate care from the beginning. In CCPs, the patient contact is limited and usually ends when a patient is assigned a care pathway and to the diagnosis-specific unit.

The initial planning of the care pathway creates the basis for managerial continuity (Haggerty et al., 2003) and facilitates continuous planning of the assigned care pathway. Managerial continuity is facilitated by the assigned care pathway which is set up by a coordinator early in the care process. In cases where a standardised care pathway is assigned, the course of care pathway should basically be known beforehand, especially if the plan is to closely follow the CCP guidelines and thereby facilitate consistent and coherent management of the care pathway. In contrast, in the customised care pathway, where the course of the care pathway is more uncertain, there is a need to discuss the pathway beforehand to ensure that all involved care providers have the same goal.

The unit coordinator complies the most with the work statement for coordinators by having an internal administrative focus. The role can be likened to a monitoring role (Mintzberg et al., 2003) that ensures that information on patients is in place and is transferred within or to other care units, that the 
care pathway runs smoothly, follows the assigned standardised or customised pathway, and monitors and follows up waiting times. Informational continuity (Haggerty et al., 2003) is a vital part of the work which can be facilitated by ensuring that information is known, passed, on and incorporated throughout the care pathway. The unit coordinator's role towards the patient is to act as a contact person for administrative enquiries such as booking appointments and to provide practical information to patients and relatives. Their relationship with the patient is similar to that of a receptionist with whom the patients sometimes communicate when visiting or calling the care unit.

Recommendations that people with complex care needs have access to a designated key contact person are becoming more common (Freijser et al., 2015, Larsson and Bjuresäter, 2016). The patient coordinator is assigned as the key contact person when a patient is referred to a diagnosis-specific unit. It is a typical liaison role (Mintzberg et al., 2003) where focus is on continuous communication and information sharing with patients to assess their needs, especially in regard to emotional support and medical needs, and to add to or customise services in the care pathway accordingly. The patient coordinator is appointed to be the eyes and ears of the patient towards other providers, for example when the patient is not present at multidisciplinary meetings, to uphold effective communication and cooperation among providers in the care pathway and to enable transfer of patient information throughout the care pathway. A patient coordinator describes it as "[patients] who have not had contact before, and it turns out to be cancerous, they get to know about me and I try to meet them and talk about my role and give them a direct [phone] number. ... [I] have contact with a dietician, curator, oncologist and others. Depending on what the patient has in the way of problems, I solve them". Using patient coordinators to establish and uphold relational continuity is consistent with previous research on the importance of having a role to facilitate relational continuity and provide support for patients (e.g. Nazareth et al., 2008, Walsh et al., 2011). The role is perceived to play a vital part to support, coordinate and navigate the patient through the healthcare system and the care pathway, and to find ways to improve care delivery for individual patients (SALAR, 2012).

All patients going through cancer diagnostics might benefit from being assigned a patient coordinator; however, providing one for all patients could be resource demanding. Coordinators advocate patient's interests, help navigate through the healthcare system, and provide additional support (RÖ, 2015). Especially in a customised care pathway, the patient coordinators could focus on ensuring that resources are used where they are needed the most.

\subsubsection{Standardised and customised care pathways in CCPs}

Findings from Paper 1 indicate that the theoretical frameworks by Bohmer (2009), Lillrank (2003), and Stabell and Fjeldstad (1998) on standardised and customised care pathways (3.4.1) comply with how pathways can be used in CCPs. A horizontal coordinator stated during an interview that assessment for pathway selection is based on the two factors symptoms and needs to acquire a holistic view of the patient from the beginning. Symptoms are matched with the alarm symptoms and needs assessment is based on elements such as physical, psychosocial, supportive, and practical needs. The standardised and customised pathways are used to respond to external variation caused by heterogeneous patient needs (Harvey et al., 1997). A summary of the characteristics of standardised and customised pathways for patients with complex care needs can be seen in Table VI. 
Table VI: Characteristics for care pathways to manage care for patients with complex care needs.

\begin{tabular}{|c|c|c|}
\hline $\begin{array}{l}\text { Care pathways for patients } \\
\text { with complex care needs }\end{array}$ & Standardised pathway & Customised pathway \\
\hline Input & $\begin{array}{l}\text { Clear symptoms agreeing } \\
\text { with alarm symptoms for } \\
\text { a certain disease } \\
\text { Less complex care needs }\end{array}$ & $\begin{array}{l}\text { Ambiguous symptoms unknown underlying } \\
\text { disease or disease agreeing with alarm symptoms } \\
\text { for e.g. SUS or CUP } \\
\text { More complex care needs }\end{array}$ \\
\hline $\begin{array}{r}\text { Course of or activities in } \\
\text { care pathway }\end{array}$ & Predictable & Undefined or changing \\
\hline $\begin{array}{r}\text { Resource and knowledge } \\
\text { intensity }\end{array}$ & $\begin{array}{l}\text { Explicit knowledge and } \\
\text { limited resources linked } \\
\text { to specified needs or } \\
\text { diagnosis }\end{array}$ & $\begin{array}{l}\text { Tacit and specialised knowledge and resource- } \\
\text { intense organisation for problem solving or linked } \\
\text { to multiple needs or diagnoses, e.g. } \\
\text { multidisciplinary teams and diagnostic centres }\end{array}$ \\
\hline Management & $\begin{array}{l}\text { Standards or routines e.g. } \\
\text { CCP-guidelines }\end{array}$ & $\begin{array}{l}\text { Standards or routines e.g. CCP-guidelines for CUP } \\
\text { or SUS } \\
\text { Problem solving, iterations }\end{array}$ \\
\hline $\begin{array}{r}\text { Coordination and support } \\
\text { need }\end{array}$ & $\begin{array}{l}\text { Lower need, mostly } \\
\text { within care unit/pathway }\end{array}$ & Higher need, for patient and within care team \\
\hline
\end{tabular}

Paper 1 further shows that the standardised pathway is used when symptoms clearly match the alarm symptoms in a CCP, and there are few or no distinct needs that ought to be taken into consideration when planning the pathway. This agrees with the presented frameworks, specifying that a patient can be assigned a standardised pathway in cases when uncertainty is low (Bohmer, 2009) meaning symptoms and/or needs are well-defined, (Lillrank, 2003, Lillrank and Liukko, 2004) easy to identify (Bohmer, 2009) and only a limited amount of adaption is needed to fulfil the needs (Stabell and Fjeldstad, 1998). A standardised care pathway often implies that the assigned pathway is more or less strictly planned according to the guidelines stated in the model pathway but with a few adaptions to take into account less complex needs.

An example provided by a CCP project leader of a patient suitable for a standardised care pathway, was a patient with a clear symptom, such as a lump in a breast, indicating a certain cancer disease, breast cancer. In this case, the course of the care pathway is predictable and CCP guidelines can be followed according to the model pathway. If the patient is a wheelchair user, transportation services can be added to the standardised care pathway but does not require extensive customisation of the pathway. It is therefore not likely that a patient with complex care needs will move through a completely standardised care pathway (Bohmer, 2005). This supports previous research stating that the standardised pathway does not imply delivery of identical care pathways (Lillrank, 2003). The sequence of diagnostic activities is standardised, but the actual execution may vary and, accordingly, so will the care pathway of individual patients. Moreover, adaptions can be made to the standardised care pathway for additional needs arising from other well-understood medical problems that can be treated independently of the main disease (e.g. Bohmer, 2005).

The analysis confirms previous studies which report that the scope of additional services is limited (Bohmer, 2009, Lillrank, 2003, Meijboom et al., 2018) to more or less homogenous diagnostics and treatment procedures, and a few additional non-medical services such as nutrition, transportation, or psychosocial support. Findings from Paper 1 indicate that CCPs have not significantly changed the way care is provided for patients in the standardised care pathway. This might be explained by the fact that many cancer diagnoses already have established care plans consistent with the content in the CCPs. The cancer diagnoses and care activities are thus not new to the organisations, and both competence and resources are already in place. CCPs are however perceived to have contributed to more patients 
experiencing a more harmonised passage through the same $\mathrm{CCP}$, which was not present before, making it possible for resources and competence to be tied to the care activities in the operational pathway.

Contrary to the standardised pathway, the customised pathway in CCPs is used for a highly diversified group of patients including patients with ambiguous symptoms which do not directly indicate a specific cancer disease and/or which have more complex care needs which must be taken into consideration when planning the care pathway. This agrees with the presented frameworks, specifying that the customised pathway should be used in cases with high uncertainty (Bohmer, 2009) where symptoms or needs are ambiguous or multiple and their cause is non-predictable (Lillrank, 2003, Lillrank and Liukko, 2004, Bohmer, 2009) and where large parts of the care pathway need to be adapted to individual needs (Stabell and Fjeldstad, 1998). The empirical result shows that in CCPs, many of the patients with ambiguous symptoms are included in the CCPs SUS and CUP.

Similar to the frameworks by Bohmer (2009), Lillrank (2003), and Stabell and Fjeldstad (1998) on standardised and customised care pathways, Paper 1 shows that cancer diagnostics for these patients is characterised by iterative work and problem solving in order to find the underlying disease (Bohmer, 2009, Stabell and Fjeldstad, 1998, Lillrank, 2003, Lillrank and Liukko, 2004). Further, the data shows that diagnostics for these patients have been facilitated by the CCP guidelines for CUP and SUS. An important difference between diagnostics for SUS and CUP and other CCPs is that the guidelines for CUP and SUS are designed and 'optimised' to identify several cancer diagnoses using the same sequence of tests and examinations. This means that the course of action is predictable for all these cases, but the outcome and next step varies depending on the result of the tests. This approach thereby differs from the 'traditional' iterative approach to diagnostics, which is usually ad-hoc and dependent on who is performing the diagnostics (Harvey et al., 1997).

The document study showed that focus in many diagnostic centres, described in Section 6.1.1, is on cancer diagnostics exclusively for CUP and SUS and not on patients who cannot follow a standardised pathway because of for example other serious diseases. Paper 1, however, provides an example of a region that developed a healthcare unit that focusses on SUS, CUP, and patients with more complex care needs. In this unit, all patients, with reasonable suspicion of cancer, are assessed based on their needs to determine whether they require a standardised or customised pathway. Those in the standardised pathway are referred 'as usual' to secondary care according to the CCP-guidelines, while those in the customised pathway (for example CUP or SUS) are diagnosed in-house by a multidisciplinary team (RÖ, 2015). Working with both standardised and customised care pathways allows for resources and multidisciplinary teams to be directed towards patients with the highest complexity needs thus increasing quality and reducing the cost of care (Bohmer, 2005, Whellan et al., 2001). A popular saying about the challenge of navigating through today's healthcare system is 'to be sick you must be relatively healthy'. The aim of the customised care pathway is to prevent this from happening by ensuring that patients with more complex care needs are identified early and properly cared for.

\subsubsection{Personalisation in care pathways}

Continuous personal contact between providers and patients is an important part of care delivery for patients with complex care needs (Schoen et al., 2009, Meijboom et al., 2018). In spite of this, previous research shows that there is a gap between the patient's personalisation needs and the personalisation provided by providers (Meijboom et al., 2018). Personalisation in this thesis is described as providers adaptation of communication and behaviour to match the patient's needs (De Blok et al., 2013).

Findings in Paper 1 highlighted that the amount of personalisation needed depends on the patient's personal characteristics. Personalisation may therefore be more or less important in both the standardised and the customised pathway and, like customisation, depends on the individual patient. As already stated in this thesis, coordination and support is an important aspect of care for patients with complex care 
needs. Some patients are very ill, or in need of multiple services during the process, and thus have a high need of support, while others are not as affected by their symptoms and have the resources to be in control of their own process, and thus have a lower need of support. The characteristics of patients following the two care pathways do suggest that patients with higher complexity care needs, such as patients with social needs or comorbidities, and who probably will follow the customised pathway, are more likely to need greater personalisation. This implies that more patients in the customised care pathway might have a greater need for personalisation.

In both Papers 1 and 2, an important finding regarding personalisation is the coordinator's role in personalising care delivery. The coordinator's opportunity to work with personalisation depends on whether or not their focus was to work directly with patients. The survey showed that the unit coordinator has the least contact with patients and only speaks with them occasionally, mostly about administrative matters such as booking appointments. In the survey, many unit coordinators specifically said they do not work with patients and that they do not strive towards creating a personal relationship with patients. Unit coordinators thereby have little opportunity to exert personalisation in their day-today work. A unit coordinator expressed "sometimes you get to talk to the patients and yes, they are, they are very upset sometimes, crying and such and so you have to take it a little easy with them if you say so". Several unit coordinators further state that their limited patient contact and knowledge about psychosocial support make these situations slightly challenging.

The horizontal coordinator, on the other hand, has limited contact with individual patients over time, because they only speak with patients on a few occasions at the most, but many horizontal coordinators speak with patients daily when assessing their needs. During the interviews, both horizontal coordinators stated that they adapted the way they talked to patients depending on how high the level of suspicion is; to emphasise or tone down the cancer suspicion; or to calm the patient's feelings about the suspected cancer such as anxiety, impatience to start the diagnostic process, nervousness, and fears. The horizontal coordinator used this conversation to customise the preliminary assigned pathway for the patient. This is consistent with Donabedian (1988) and a study on customisation and personalisation in elderly care by De Blok et al. (2013) which both state that interpersonal relationships and personalisation could be an enabler for improved technical quality or customisation. Creating a personal relationship between the care providers and elderly enabled the elderly to talk about their wants and needs thereby revealing potential needs which necessitated rearranging or customising their received services (ibid).

The patient coordinator is the one with the most patient contact. Previous research supports this finding that most contact and personalisation occur with nurses and secretaries, and that these staff are more focused on developing a personal relationship with the patient (Meijboom et al., 2018, Freijser et al., 2015). Patient coordinators have regular contact with patients to talk about their care pathway and they are thereby essential for personalisation. The patient coordinators state, both in the interviews and Paper 1, that personalisation is part of their job description, and that they would like to work more with personalisation but that there is not always enough time.

All three coordinator roles stated that a majority of the patients appreciated the opportunity to ask questions, raise any concerns, and to have a personal contact in the healthcare system. This is in line with other studies which highlight that patients request personalisation in how they are approached, in forming relationships with their providers, and that they do not want to be reduced to their medical needs but to be acknowledged as a person with feelings and lives outside of their care (Meijboom et al., 2018). These findings support the previous research stating that personalisation can be applied both ex situ when the managing the care pathway for the patient (Piller, 2007, De Blok et al., 2013) and in situ when interacting with the patient (Gwinner et al., 2005). 


\subsection{Quality of care}

The second research question in this thesis is how can these practices (coordination, standardisation, customisation, and personalisation) influence quality of care? This question will be answered through discussing the framework presented in Figure 4 which shows the application of the empirical context in the Quality of Care Framework.

In this thesis, the elements derived and assessed from the structure are coordinators and the CCPs. Coordinators, presented in Chapter 2, was implemented to support quality of care for cancer patients and this is way it is interesting to assess their potential contribution to quality of care. Further, CCPs is seen as an organising principle by being a new fundamental and holistic view of how to deliver cancer diagnostics. In healthcare, care pathways have been increasingly used as an approach to structure operational care delivery processes around individual patient groups (Vanhaecht et al., 2010). On the conceptual level, working with care pathways can therefore be compared to a light version of process orientation.

The elements derived from the process is the practices coordination, standardisation, and customisation and personalisation. Standardisation and customisation is primarily discussed in terms of the standardised and customised care pathways and coordination in terms of coordinators. The outcomes, or quality dimensions, assessed are accessibility, timely, equitable, and patient-centred. The quality dimensions should not be seen as separate aspects, but they may overlap, and the same practice may influence several dimensions.

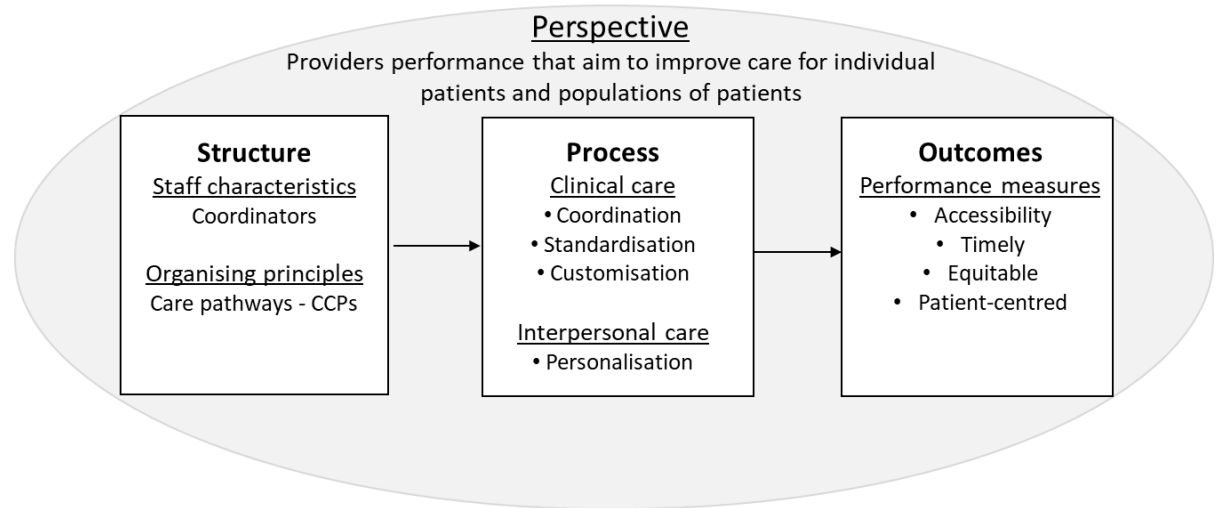

Figure 4: Application of the empirical material to the Quality of Care Framework.

\subsubsection{Access to care}

As previously stated, access to care is described as availability of services, the ability of the structure and processes to meet the patient's differentiated service needs and access to services, and the ability to admit patients and match structure and processes to their differentiated service needs (Campbell et al., 2000). Access can be assessed on both the individual patient and the population level.

Availability of services can be described as the ability of the structure and processes to provide a variation of services, providers, specialisations and so forth to meet the patient's differentiated service needs. As previously pointed out, the service needs varies greatly between the standardised and customised care pathway. The CCP-guidelines specify the minimum requirement of differentiated services and providers that should be included in the standardised care pathway. This implies that all hospitals delivering cancer care need to fulfil these minimum requirements for each CCP. Instead of all hospitals providing all CCPs, both national and regional divisions have been made to focus resources 
and increase availability of certain services. One example is the CCP for penile cancer, which has only a few patients per year and care provision is located at one hospital. Availability of services needed in the customised pathway is more difficult to specify because the needs vary greatly between patients. For instance, a horizontal coordinator expressed difficulties in regularly accessing dietitians and rehabilitation services, since they are not assigned to work with CCPs. Securing and allocating the resources to be included in the standardised pathway can thus largely be made because of the CCP guidelines. However, since the services needed in the customised pathway are more difficult to predict a solution could be to share more specific resources or specialisations between the CCPs to secure that they are available if needed.

A challenge related to availability of services is the lack of capacity and staff described in Paper 3. A nationwide lack of capacity and staff, particularly of physicians and specialist nurses, in areas such as radiology, pathology and urology limits the availability of services. This lack seem to particularly affect multidisciplinary meetings because not all specialities attend due to lack of available specialists. This undermines the multidisciplinary debate and poses the risk of insufficient diagnostics (Rosell et al., 2018).

Access to services can be described as the ability to admit patients and match structure and processes to their differentiated service needs. At the population level, standardised alarm symptoms are used to decrease the uncertainty as to which patients should be referred to care (Larsen et al., 2013, Jensen, 2015). In CCPs, the aim of introducing alarm symptoms is early detection and to decrease previously experienced problems of patients being sent back and forth between primary and secondary care without receiving a diagnosis (NBHW, 2018) which posed the risk of a prolonged patient care process that required many resources from the providers (Coleman, 2003). Paper 1 indicates that introducing alarm symptoms has increased access for all CCP patients but especially those with ambiguous symptoms such as SUS and CUP. Further, before CCPs suspected cancer was generally not clearly expressed when general practitioners referred patients to secondary care. The possibility to be referred greatly depended on individual general practitioners; and being admitted to secondary care depended on interpretation and assessment by individual physicians. Patients with ambiguous symptoms thereby had an increased risk of being excluded from care due to the complexity of diagnostics and of finding the cause of the symptoms. With CCPs, routines are clearer, and fulfilling an alarm symptom means guaranteed priority access to secondary care. The alarm symptoms are perceived to decrease the risk for exclusion which implies that access to care has increased for these patients. In addition, the survey shows that alarm symptoms are perceived to have also highly influenced the quality dimensions timely and equitable care.

Improved access to care is however not only discussed in positive terms. There is an ongoing discussion about how guaranteed access to care impacts access for other patient groups. Around 111,000 patients were included in a CCP during 2018, of which around 35\% started cancer treatment (Regional Cancer Centre in Coorporation, 2019). A high number of patients therefore undergo cancer diagnostics when they do not have cancer. Findings in Papers 1 and 3 revealed that one reason for the high number of patients undergoing diagnostics is the broad spectrum of alarm symptoms which also cover noncancer patients. One example is the CCP for bladder cancer where only $11 \%$ of a total of 16,800 patients start treatment in contrast to acute lymphocytic leukaemia where $93 \%$ of a total of 55 patients start treatment (Regional Cancer Centre in Coorporation, 2019). Opinions differ on whether the positive aspects of including 'too many' patients, such as finding patients not only with cancer but with other serious diseases (RÖ, 2018), outweigh the negative, such as longer waiting times for patients with a lower care need. However, a general finding is the perception that the number of patients included in CCPs without cancer will decrease as routines for working with alarm symptoms fall into place and the alarm symptoms are modified based on statistics over the symptoms that actually lead to a cancer diagnosis. 
On the individual patient level, the care pathway needs to be matched with the patient's needs to provide a more or less standardised or customised care pathway. However, misassignment to a pathway, resulting from inadequate assessment or misinterpretation of information (Lillrank and Liukko, 2004), could result in a patient following a customised pathway when they should have followed a standardised pathway, and vice versa. The case study imply that patients in need of a standardised pathway can, without difficulties, follow a customised pathway. However, a patient in need of a customised pathway who follows a standardised pathway could experience insufficient or inappropriate care and longer waiting times. One example, provided during the interviews by a CCP project leader, was that patients who were totally excluded from CCPs were often not given prioritisation and thereby experienced longer waiting times. This is supported by Potter et al. (2007) and Jensen et al. (2015) who studied waiting times for patients excluded from a care pathway, and Chan et al. (2018) who evaluated health outcomes for high severity of illness patients who were sent either to an intermediate post-emergency care unit or an intensive care unit. The study by Chan et al. (2018) showed that the high severity patients received insufficient care and thereby inferior health outcomes when placed in the post-emergency unit. However, substantial outcome improvements were achieved for low severity of illness patients who were sent to the same unit (ibid). This thesis, along with previous research, further highlights the need to separate the patient with complex care needs to ensure that they receive appropriate care.

\subsubsection{Timely care}

In theory, access can be seen as a prerequisite to achieve timely care (Campbell et al., 2000). At the population level, the empirical data point towards three components of CCPs which are perceived in particular to increase timeliness of CCPs: alarm symptoms, facilitating early detection and diagnosis; pre-scheduled timeslots, enabling quick access to tests and examinations; and maximum waiting time limits, specifying the medically and organisationally appropriate timeframes. These limits provide patients and providers with information about the waiting times and sense of urgency that can be expected in the care process. Coordinators in both the survey and case study state that for some patients the information on expected waiting time is more important than rapid care. Another aspect raised by the coordinators is that some patients perceive the CCPs to be too quick, and some patients are not mentally ready. This opens up for questions as to whether there is a risk that these strategies for timely care may also negatively influence a patient's perception of quality of care. Coordinators also state that it is important to give these patients sufficient support and information during the care pathway. This is in line with results from other scholars (Sanson-Fisher et al., 2000).

In addition, coordinators, especially unit coordinators, perceive that they contribute to reducing waiting times. The reason might be that unit coordinators have a more outspoken focus on monitoring and following up waiting times. By customising the care pathway, the process can be pushed to go faster or reduced to go slower. Patients following CUP and SUS are often very ill, due to rapidly progressing or advanced cancer, for example, and might be too sick to follow a standardised pathway. Care must not be provided too slowly, which could pose a risk to the patient's health, or too rapidly hoping to improve care outcomes (RÖ, 2015).

Achieving timely care for individual patients is not only a matter of access but also what the patient perceives as timely care. The aim of the CCPs to provide care within the maximum waiting times sometimes creates conflict between the patient's preferences or prerequisites. The case study and survey revealed that not all patients want or are medically able go through a rapid diagnostic process. One phenomenon is patient-chosen-waiting when patients themselves postpone care for either a shorter or longer time because they want to take a vacation or need time to process the diagnosis. The survey shows that opinions differ on whether these patients should be excluded from CCPs or not. Another case is patients who are too ill to be pushed through a care pathway where health status can affect the ability of a patient to undergo surgery, for example. Both of these cases could benefit from following a customised 
care pathway in which they can get the support they need. However, it could also entail longer waiting times for them.

Paper 3 highlights the ongoing discussion at a population level, regarding the concept crowding-out effects which refers to situations where patients with a lower priority receive care before those with a higher priority, causing longer waiting times for patients in more urgent need of care (NBHW, 2016). This patient 'queue jumping' is perceived to cause negative effects for other patients especially in terms of longer waiting times. However, due to the complexity of assessment, there is a lack of evidence that the crowding-out effect does occur. Papers 2 and 3, however, showed that a majority of coordinators and all regions percieve that crowding-out occurs. This is an important issue to study to prevent crowding-out effects in the healthcare system, and to ensure that not only the patients in most urgent need of care are given priority but that resources can be planned and allocated where they are most needed.

\subsubsection{Equitable care}

The golden rule of healthcare is good health and care on equal terms for the whole population and that the patient with the highest care need should be the first to receive care (Government Offices Of Sweden, 1982). This statement implies that equitable care is always a comparison of individuals within a population (Campbell et al., 2000). Equity should be achieved both horizontally, between different services or patient groups, and vertically, within the same service or patient group (NBHW, 2016).

The empirical data indicate that before the introduction of CCPs, patients, particularly those in vulnerable patient groups, risked being consciously or unconsciously excluded from cancer diagnostics because of factors such as unspecific symptoms, low socioeconomic status, disabilities, age or language barrier. These findings agree with those of other authors (RÖ, 2014, NBHW, 2015a, Tinghög et al., 2014). A horizontal coordinator states "those patients who we have in [the unit] now, who are really sick, have to wait a long time for their [test] response. ... they are not prioritized [in the healthcare system] because there is not a clear suspicion of breast cancer or colon cancer, they [the symptoms] are a bit diffuse but they are super sick. Why should the sickest be pushed away just because they are not identified?" Their medical status often means that these patients are incapable of fighting for their right to equitable care, and their complex care need, requiring extensive resources, could also delay their care process due to lack of capacity and personnel resources in the healthcare system. By extension, this implies that more healthy and flexible patients may therefore have shorter waiting times due to their ability to attend any appointment time offered to them. Coordinators are perceived as valuable resources who can act as advocates for vulnerable patients, and can help mediate the vulnerable state that hampers their chances of receiving equitable care.

As previously described, the practice standardisation is commonly used to decrease unwarranted variation between providers (Mercuri and Gafni, 2011). Both the alarm symptoms and CCP-guidelines are perceived to make care more equitable for the whole population between patients in the same CCP, vertically, and in different CCPs, horizontally. Horizontal inequity is the most difficult to remedy due to the challenge of acquiring an overview of and follow up of patients throughout their care pathway (Tinghög et al., 2014). Horizontally, nationally established maximum waiting times define the urgency of diagnostics for different cancer diagnoses.

The case study show that, in the initial stage of the care pathway, when assessing urgency and booking initial appointments, horizontal coordinators work with prioritisation between patients both horizontally and vertically. Paper 1 shows that being located at a centralised location enables the horizontal coordinator to be more 'objective' towards the different patient groups, facilitating a more unbiased evaluation of each patient and thereby able to plan and allocate resources where they are most needed. Vertically, cancer diagnostics is no longer a subjective judgment of individual providers but is built on nationally unified diagnostics for each cancer diagnosis. According to the survey, unit 
coordinators attempt to facilitate vertical equity by making prioritisations between patients in individual CCPs or units when booking appointments.

Achieving equitable care in practice is, however, not an easy matter. Following a CCP means being prioritised throughout the care pathway but medical needs should always be the discriminator. In the survey, $33 \%$ of coordinators state that they often need to prioritise patients. A coordinator expressed the challenge when rebooking a last-minute cancellation of a morning appointment. The choice stood between calling in a 45-year old mother with small children who could easily make it on time or a 95year old patient in need of a lot of assistance who might not make it on time. According to the medical need, the older patient should have been called in. The dilemma was choosing between equitability and resource efficiency. This implies that there might be situations where it might be necessary to consciously sidestep the equity rule to ensure that available resources are used in an effective way.

\subsubsection{Patient-centred care}

Patient-centred care can be described as providers identifying, respecting, and managing patient differences, values, preferences, and expressed needs (Knebel and Greiner, 2003), inviting patients to actively participate in care (Lusk and Fater, 2013), and delivering individually customised information (NBHW, 2006). Using patient-centred care as a quality dimension underlines the importance of seeing patients as customers and not as passive care takers (Berwick, 2009).

As previously discussed, the findings in Paper 1 is in line with previous research (Vanhaecht et al., 2010) stating that the standardised care pathway does not imply that all patient pathways are the same. Standardisation is about standardising the sequence of that CCP, not about how behave towards patients or performing individual care activities. This implies a shift in the provider's focus towards delivering the pathway content and less on deriving its course. However, not everyone sees it this way. Contrary to Epstein and Street (2011) saying that the debate on the conflict of standardisation of evidence based medicine (such as CCP guidelines) vs individual needs has been laid to rest, several comments from coordinators in the survey mention the use of CCP with no provision of customisation. This indicates that there is still a need to resolve how to relate the CCPs to differing patient preferences or needs.

Paper 1 points out that CCPs are also used as an interface document, specifying responsibilities and crossing points between providers, which is perceived to contribute to improved safety and continuity in the care pathway. Coordinators in the case study explain that their focus on informational continuity has increased both towards patients, since information about the care pathway is known on beforehand, and providers, since the referral path is clear. Moreover, Paper 1 shows that collaboration between healthcare providers has increased and forums such as multidisciplinary meetings create opportunity to discuss individual patients. One major challenge is still to connect providers in primary care with those in secondary care. Horizontal coordinators put emphasis on coordinating the early parts of the care pathway and use this position to act as integrators (e.g. Galbraith, 1974) to strengthen the link between the two care levels. Horizontal coordinators state that both they and the patients experience improved coordination and a feeling that they are being taken care of from the start.

An interesting finding from the survey is that coordinators perceive only a low contribution to more individualised care. One explanation for this might be the interpretation of the term individualisation, whether it is interpreted as customisation of medical or non-medical care. Some coordinators state that patients accept the appointments and recommendations given to them by their physicians and this is why no customisation is needed. The lack of comments about non-medical customisation or even personalisation implies that this perhaps does not come to mind in relation to individualisation. It might also be that coordinators, especially unit coordinators who mostly have an administrative role, do not have a mandate to customise the care pathway, and customisation is only executed if requested by physicians or nurses. 
Asking for a statement about patient needs or claiming to work with customised care pathways is not enough to achieve patient-centred care, the needs should also be taken into consideration to adapt the care pathway. In a best-case scenario, the healthcare system should naturally be able to accommodate differences in patient preferences, encourage shared decision making, and be able to anticipate patient needs, rather than simply reacting to events (Institute of Medicine, 2001, Epstein and Street, 2011). During one of the observation studies at a multidisciplinary meeting, a situation was observed where no one knew the patient's preferences for treatment. Was the patient willing to undergo surgery at this high age? How was the patient's health? Had anyone in the room met the patient? This situation clearly showed an unawareness about the individual patient's preferences. Having a patient coordinator in the room who had met with the patient could have solved the problem which resulted in a delayed treatment plan.

Previous research highlights provider behaviours such as communicating and listening, and treating the patient as a unique individual, as important drivers to achieve patient-centred care (Lusk and Fater, 2013, Bayliss et al., 2008). This corresponds well to the practice personalisation and implies that personalisation can be an enabler for patient-centred care. In addition, findings from previous studies suggest components including continuity of relationships with care providers such as coordinators, convenient access to providers, and communication about customised care plans are important for patient-centred care (Bayliss et al., 2008). The previous sections have already pointed out coordinators as an important means to achieve coordination and personalisation. Several coordinators state "My work is to have the patient in focus [...] I do everything to make the patient feel safe and satisfied". However, what is meant by having the patient in focus is not specified. Convenient access to providers is mentioned by all three coordinator roles where a direct phone line to a coordinator is commonly mentioned as a way to communicate with patients outside of their hospital visits. A horizontal coordinator expresses in the survey "[patients are] very grateful that I call and inform about the next care step, [I] perceive that they are relieved when I call and also can provide them with a phone number to call me anytime in case they have any questions, it is nice to have a [phone] number to someone when additional questions arise afterwards". Being available to patients might be a way to strengthen the relational continuity between coordinators and patients (Haggerty et al., 2003).

Findings from the survey indicate that patients want to be kept informed, by asking for information about the following steps of the pathway, and they want to take part in decisions concerning appointments and examinations. This is in line with previous research showing that many patients want to take a more active role in their care pathway (Elg et al., 2012, Crawford et al., 2002). Many coordinators work with booking and guiding patients through the healthcare system and selfassessments show that coordinators perceive that they, to some extent, contribute to keeping patients well-informed and increasing patient participation. 


\section{Conclusions, contributions and future research}

The purpose of this thesis was to contribute with knowledge on how healthcare can be managed for patients with complex care needs. This chapter presents the conclusions of this thesis, contributions, and suggestions for future research.

\subsection{Conclusions}

In this thesis, the studied patient group is patients with complex care needs, a patient group characterised by high variation in needs, uncertainty in how care should be organised to assess and fulfil these needs, and the need of care from multiple providers. The first research question discussed how care pathways can be managed using the practices coordination, standardisation, customisation, and personalisation for patients with complex care needs.

Care pathways are increasingly used as a means to define the sequence of care activities and involved providers. In this thesis, it is argued that care pathways are much more than that as they also contribute with a systematic process view which is currently not a generally applied approach to care delivery. This more or less unintended operationalisation of the process view is used to guide providers in their day-to-day work and is similar to process orientation, to centre care around the patient and to standardise the service sequence with the aim to provide timely and patient-centred care.

Previous research has highlighted the need to empirically study standardised and customised care pathways (Bohmer, 2009, Lillrank and Liukko, 2004). This thesis argues that there is a need to combine standardised and customised care pathways to manage care for patients with complex care needs. The need for standardised and customised pathway varies depending on the complexity of the patient's care and support needs. The standardised pathway is fundamentally based on national guidelines for a certain disease and allows slight adaptions which do not directly affect the course or pace of the care pathway. If extensive adaptions are needed, it is considered to be a customised care pathway. This thesis argues that the customised pathway in particular benefits patients with serious unspecific symptoms, unknown primary tumour or more complex care needs as patients with comorbidities or limited ability to perform basic daily functions.

Further, this thesis argues that coordinators are an important means to manage coordination, customisation, and personalisation in the care pathway. The coordinator's role is twofold - to manage care pathways and to support patients. Three coordinator roles are identified each with their own focus. All coordinators have a vital role in coordinating the providers in the care pathway and facilitate the smooth and timely running of the planned pathway. Unit coordinators focus on administrative support for patients and providers within a care unit or for some care pathways, and horizontal coordinators focus on symptoms and needs assessment and preliminary planning of the assigned care pathway. Patient coordinators act as an advocate for patients in need of additional support and continuous needs assessment throughout the care process.

Interactions with patients is an important part of managing care for patients with complex care needs This thesis argues that there is need not only for customisation, but also for personalisation of the care pathway by adapting the interpersonal communication with patients to make them feel like unique individuals. The need for personalisation is perceived to increase with more complex care need; however, it needs to be assessed for each patient. An important finding, supporting previous research by Meijboom et al. (2018) on personalisation, is the opportunity for patient and horizontal coordinators to create personal relationships with patients which can enable customisation in the care pathway. Unit coordinators, who work less with patients, may still practice personalisation when supporting patients with administrative matters which can be used for example to adapt the time of day for appointments or to acquire transport to the hospital. 
The second research question discussed the influence of the practices (coordination, standardisation, customisation, and personalisation) on the quality of care dimensions accessibility, timeliness, equitability and patient-centredness.

Access to care refers to the availability of and access to services. This thesis argues that the CCP guidelines positively influence availability of care services by harmonising the availability of services and the resources needed in the standardised care pathways for patients following the same CCP. Availability of services in the customised pathway is however limited and varies between units. This has a possible negative effect on availability of certain services which is partly perceived to be an effect of the wide-ranging lack of capacity and staff in the healthcare system. Care coordinators also have a vital role in assigning patients to the 'right' care pathway since patients in need of customised care pathways are perceived to have worse outcomes if placed in a standardised care pathway without proper support. This thesis argues that the introduction of alarm symptoms specifying which symptoms indicate cancer and should be given priority is perceived to have positively influenced access to care services. Further this thesis argues that the alarm symptoms have had a crucial influence on access to services for patients with ambiguous or vague symptoms. There is, however, an ongoing debate as to whether guaranteed access to care exclusively for one patient group negatively impacts access to care for other patient groups.

Timely care means receiving care at the right time. This thesis argues that components in the standardised care pathway such as alarm symptoms facilitating early detection, pre-scheduled timeslots, providing prioritised access to appointments and maximum waiting time limits are all perceived to positively influence timely care. A customised care pathway can enable adjustment of the care pathway so that it can move more quickly or more slowly, depending on the patient's health status. In addition, patients may also influence the timeliness of care by asking to postpone care. Coordinators, especially unit coordinators, are perceived to contribute to timeliness in the care pathway by increasing continuity and following up on waiting times. Providing prioritisation and more timely care for patients with complex care needs may however lead to longer waiting times for other patients.

Equitable care means sufficient care provided to each patient to meet their individual needs and is assessed at the population level. This thesis argues that standardisation of care activities such as symptom assessment and delivery of diagnostics has positively influenced efforts to achieve equitable care on both the horizontal and vertical level. Further, this thesis argues that customisation of care pathways has also positively contributed to more equitable care by allowing patients in need of additional attention more support throughout their care pathway. Coordinators have an important role to continuously assess patient needs and to manage so that the patient in most need of care receives it. Horizontal coordinators make initial urgency assessments and prioritisations, and patient and unit coordinators work more within the same unit or pathway. Ethical considerations of prioritisations between patients are, however, a daily challenge for many coordinators.

Patient-centred care can be described as providers striving to identify, respect, and manage patient needs, inviting patients to actively participate in care, and delivering individually customised information. This thesis argues that care pathways and coordination among care providers can positively influence patient-centred care by shifting the focus from what to deliver to how to deliver it. Customisation can increase patient-centred care by adapting the care pathway to the unique need of each patient. However, there is still a misconception among some coordinators that standardising care pathways implies that care should not be customised. Further this thesis argues that personalisation in terms of communicating with and listening to patients is an important practice used to improve relational continuity and thereby contribute to patient-centred care. Coordinators also positively influence patient-centred care, including both informational and relational continuity, by providing patients with necessary information and inviting them to participate in decisions in their care pathway. 


\subsection{Theoretical contributions}

The aim of this thesis has been to contribute with knowledge on how care pathways can be managed for patients with complex care needs. To achieve this, service management literature has been combined with healthcare literature. From a theoretical point of view, this thesis especially contributes with knowledge on the role of care pathways for providing standardised and customised care processes. The process view of care pathways have been addressed before but by providing another example by applying it to CCPs it might contribute an increased knowledge on how process orientation can be applied in healthcare.

This thesis also contributes with knowledge on how service concepts such as standardisation and customisation (e.g. Lampel and Mintzberg, 1996) can be used to support care pathways in healthcare delivery. This thesis suggests that this combination can be used to both reduce variation, by being applied to specific patient groups, and respond to variations by considering individual patient needs.

It is also one of the first studies, to the author's knowledge, that systematically combine the concepts standardisation, customisation, coordination, and personalisation and translates them into healthcare context. In addition, this thesis provides insights on how the practices influence quality of care what are the strengths and weaknesses of the practices in relation to care pathways.

\subsection{Managerial contributions}

From a managerial point of view, this thesis contributes with empirical illustrations of how care can be managed for patients with complex care needs. Provision of care that considers both the patient's medical and non-medical needs is likely to become more and more important in healthcare as the population care needs become increasingly complex. The findings in this thesis are relevant for healthcare managers and researchers interested in designing, implementing, or researching alternative healthcare strategies based on holistic needs assessment and care delivery. This thesis presents concrete examples of which type of patients benefit from standardised and customised care by applying it to CCPs. In addition, this thesis proposes the introduction of coordinators and personalisation as a means to further enhance coordination and continuity and to enable customisation in the care delivery process.

\subsection{Future research}

This thesis has discussed how care can be managed for patients with complex care needs. One perspective that has not been included is that of the patients. This perspective is vital to gain a deeper understanding of how the principles could be used to improve care delivery. By doing so, knowledge could be gained about what aspects of the care pathway the patient considers could be of use if the care pathway needs to be customised and how greater personalisation can be achieved. The patient perspective is also important if we are to understand how to fulfil their coordination and support needs and evaluate their perception of quality of care.

Another interesting subject is patient satisfaction. Asking patients about their view on value and quality of care, based on their particular conducted care pathway, could provide information as to patients consider important when designing care pathways or coordination.

In this thesis, three versions of the coordinator role were analysed. Each role could be studied further to provide a more detailed understanding of how they could be developed to improve coordination, customisation and support for patients in different levels of the healthcare system.

The practices presented in this thesis are just a fraction of the available practices. Other practices which could be interesting to research further include modularity where the pathway is divided into subprocesses which can be individually developed and improved, multidisciplinary teams or networks where medical teams gather around the patient to collaboratively deliver care to the patient, and so forth. 


\section{References}

Anell, A. (2005) Swedish healthcare under pressure. Health Economics, 14(S1), pp. 237-254.

Askildsen, J.-E., Holmås, T. H. \& Kaarboe, O. (2011) Monitoring prioritisation in the public health-care sector by use of medical guidelines. The case of Norway. Health Economics, 20(8), pp. 958970.

Axelsen, K. R., Nafei, H., Jakobsen, S. F., Gandrup, P. \& Knudsen, J. L. (2014) Coordinators experience better pathways for cancer patients after the introduction of the coordination function for pathways [In Danish]. Ugeskrift for Laeger, 176.

Babrow, A. S., Kasch, C. R. \& Ford, L. A. (1998) The many meanings of uncertainty in illness: Toward a systematic accounting. Health Communication, 10(1), pp. 1-23.

Bagshaw, S. M., Opgenorth, D., Potestio, M., Hastings, S. E., Hepp, S. L., Gilfoyle, E., Mckinlay, D., Boucher, P., Meier, M., Parsons-Leigh, J., Gibney, R. T. N., Zygun, D. A. \& Stelfox, H. T. (2017) Healthcare Provider Perceptions of Causes and Consequences of ICU Capacity Strain in a Large Publicly Funded Integrated Health Region: A Qualitative Study. Critical Care Medicine, 45(4), pp. 347-356.

Bamford, D. R. \& Forrester, P. L. (2003) Managing planned and emergent change within an operations management environment. International Journal of Operations \& Production Management, 23(5), pp. 546-564.

Barlow, L., Westergren, K., Holmberg, L. \& Talbäck, M. (2009) The completeness of the Swedish Cancer Register-a sample survey for year 1998. Acta Oncologica, 48(1), pp. 27-33.

Barry, M. J. \& Edgman-Levitan, S. (2012) Shared decision making-the pinnacle of patient-centered care. New England Journal of Medicine, 366(9), pp. 780-781.

Batalden, P. B. \& Stoltz, P. K. (1995) Quality management and continual improvement of health care: A framework. Journal of Continuing Education in the Health Professions, 15(3), pp. 146-164.

Bayard, J. M., Calianno, C. \& Mee, C. L. (1997) Care coordinator - Blending roles to improve patient outcomes. Nursing Management, 28(8), pp. 49.

Bayliss, E. A., Edwards, A. E., Steiner, J. F. \& Main, D. S. (2008) Processes of care desired by elderly patients with multimorbidities. Family Practice, 25(4), pp. 287-293.

Beattie, M., Shepherd, A. \& Howieson, B. (2013) Do the Institute of Medicine's (IOM's) dimensions of quality capture the current meaning of quality in health care? An integrative review. Journal of Research in Nursing, 18(4), pp. 288-304.

Begun, J. W. \& Kaissi, A. A. (2004) Uncertainty in health care environments: Myth or reality? Health Care Management Review, 29(1), pp. 31-39.

Bergman, B. \& Klefsjö, B. (2010) Quality from Customer Needs to Customer Satisfaction, Lund, Studentlitteratur.

Berwick, D. M. (2009) What 'patient-centered'should mean: confessions of an extremist. Health Affairs, 28(4), pp. 555-565.

Bickell, N. A. \& Young, G. J. (2001) Coordination of care for early-stage breast cancer patients. Journal of General Internal Medicine, 16(11), pp. 737-742.

Bird, S. R., Kurowski, W., Dickman, G. K. \& Kronborg, I. (2007) Integrated care facilitation for older patients with complex health care needs reduces hospital demand. Australian Health Review, 31(3), pp. 451-461.

Bodenheimer, T. \& Berry-Millett, R. (2009) Care management of patients with complex health care needs. Research synthesis report no. 19. San Francisco: Center for Excellence in Primary Care, Department of Family and Community Medicine, University of California.

Bohmer, R. M. (2005) Medicine's service challenge: blending custom and standard care. Health Care Management Review, 30(4), pp. 322-330.

Bohmer, R. M. (2009) Designing care: aligning the nature and management of health care, Boston, Harvard Business Review Press

Bowen, G. A. (2009) Document analysis as a qualitative research method. Qualitative Research Journal, 9(2), pp. 27-40.

Brennan, T. A., Leape, L. L., Laird, N. M., Hebert, L., Localio, A. R., Lawthers, A. G., Newhouse, J. P., Weiler, P. C. \& Hiatt, H. H. (1991) Incidence of adverse events and negligence in 
hospitalized patients: results of the Harvard Medical Practice Study I. New England Journal of Medicine, 324(6), pp. 370-376.

Brook, R. H., Mcglynn, E. A. \& Shekelle, P. G. (2000) Defining and measuring quality of care: a perspective from US researchers. International Journal for Quality in Health Care, 12(4), pp. 281-295.

Brouwers, M., Oliver, T., Crawford, J., Ellison, P., Evans, W., Gagliardi, A., Lacourciere, J., Lo, D., Mai, V. \& Mcnair, S. (2009) Cancer diagnostic assessment programs: Standards for the organization of care in Ontario. Current Oncology, 16(6), pp. 29.

Bryman, A. (2001) Social Research Methods, Oxford, Oxford University Press.

Butow, P., Price, M. A., Shaw, J. M., Turner, J., Clayton, J. M., Grimison, P., Rankin, N. \& Kirsten, L. (2015) Clinical pathway for the screening, assessment and management of anxiety and depression in adult cancer patients: Australian guidelines. Psycho-Oncology, 24(9), pp. 9871001.

Bylund, C. L., Peterson, E. B. \& Cameron, K. A. (2012) A practitioner's guide to interpersonal communication theory: An overview and exploration of selected theories. Patient Education and Counseling, 87(3), pp. 261-267.

Campbell, H., Hotchkiss, R., Bradshaw, N. \& Porteous, M. (1998) Integrated care pathways. BMJ: British Medical Journal, 316(7125), pp. 133-137.

Campbell, S. M., Roland, M. O. \& Buetow, S. A. (2000) Defining quality of care. Social Science \& Medicine, 51(11), pp. 1611-1625.

Cancer Institute NSW (2011) Evaluation of the role of cancer care coordinator - Summary report. Sidney.

Capitman, J. (2003) Effective coordination of medical and supportive services. Journal of Aging and Health, 15(1), pp. 124-164.

Cargill, C. F. (1989) Information technology standardization: Theory, process, and organizations, Bedford, MA: Digital Press.

Caris-Verhallen, W. M., De Gruijter, I. M., Kerkstra, A. \& Bensing, J. M. (1999) Factors related to nurse communication with elderly people. Journal of Advanced Nursing, 30(5), pp. 1106-1117.

Chan, C. W., Green, L. V., Lekwijit, S., Lu, L. \& Escobar, G. (2018) Assessing the impact of service level when customer needs are uncertain: An empirical investigation of hospital step-down units. Management Science, 65(2), pp. 751-775.

Chaudhuri, A. \& Lillrank, P. (2013) Mass personalization in healthcare: insights and future research directions. Journal of Advances in Management Research, 10(2), pp. 176-191.

Cheah, J. (2000) Clinical pathways-an evaluation of its impact on the quality care in an acute care general hospital in Singapore. Singapore Medical Journal, 41(7), pp. 335-346.

Christensen, M., Rosenberg, M., Mahon, E., Pineda, S., Rojas, E., Soque, V. \& Johansen, M. L. (2016) Pivot nursing: an alternative to traditional ed triage. Journal of Emergency Nursing, 42(5), pp. 395-399.

Coleman, E. A. (2003) Falling through the cracks: challenges and opportunities for improving transitional care for persons with continuous complex care needs. Journal of the American Geriatrics Society, 51(4), pp. 549-555.

Coleman, E. A. \& Boult, C. (2003) Improving the Quality of Transitional Care for Persons with Complex Care Needs. Journal of the American Geriatrics Society, 51(4), pp. 556-557.

Condelius, A., Edberg, A.-K., Jakobsson, U. \& Hallberg, I. R. (2008) Hospital admissions among people $65+$ related to multimorbidity, municipal and outpatient care. Archives of Gerontology and Geriatrics, 46(1), pp. 41-55.

Cortis, L. J., Ward, P. R., Mckinnon, R. A. \& Koczwara, B. (2017) Integrated care in cancer: What is it, how is it used and where are the gaps? A textual narrative literature synthesis. European Journal of Cancer Care, 26(4), pp. 1-17.

Coyle, Y. M. \& Battles, J. (1999) Using antecedents of medical care to develop valid quality of care measures. International Journal for Quality in Health Care, 11(1), pp. 5-12.

Crawford, M. J., Rutter, D., Manley, C., Weaver, T., Bhui, K., Fulop, N. \& Tyrer, P. (2002) Systematic review of involving patients in the planning and development of health care. BMJ: British Medical Journal, 325(7375), pp. 1263-1268. 
Dahlgaard, J. J., Pettersen, J. \& Dahlgaard-Park, S. M. (2011) Quality and lean health care: A system for assessing and improving the health of healthcare organisations. Total Quality Management \& Business Excellence, 22(6), pp. 673-689.

Davenport, T. H. (1993) Process innovation: reengineering work through information technology, Boston, Harvard Business School Press.

De Blok, C., Meijboom, B., Luijkx, K. \& Schols, J. (2013) The human dimension of modular care provision: opportunities for personalization and customization. International Journal of Production Economics, 142(1), pp. 16-26.

De Blok, C., Meijboom, B., Luijkx, K., Schols, J. \& Schroeder, R. (2014) Interfaces in service modularity: a typology developed in modular health care provision. Journal of Operations Management, 32(4), pp. 175-189.

De Regge, M., Gemmel, P., Verhaeghe, R., Hommez, G., Degadt, P. \& Duyck, P. (2015) Aligning service processes to the nature of care in hospitals: an exploratory study of the impact of variation. Operations Management Research, 8(1-2), pp. 32-47.

Dean, J. W. \& Bowen, D. E. (1994) Management theory and total quality: Improving research and practice through theory development. Academy of management review, 19(3), pp. 392-418.

Deming, W. E. (1991) Out of the Crisis, Cambrigde, Cambrigde University Press.

Donabedian, A. (1966) Evaluating the quality of medical care. The Milbank memorial fund quarterly, 44(3), pp. 166-206.

Donabedian, A. (1988) The quality of care. How can it be assessed? JAMA: The Journal of the American Medical Association, 260(12), pp. 1743-1748.

Donabedian, A. (1990) The seven pillars of quality. Archives of pathology \& laboratory medicine, 114(11), pp. 1115-1118.

Donabedian, A. (2002) An introduction to quality assurance in health care, Oxford, Oxford University Press.

Dubois, A. \& Gadde, L.-E. (2002) Systematic combining: an abductive approach to case research. Journal of business research, 55(7), pp. 553-560.

Dubuc, N., Bonin, L., Tourigny, A., Mathieu, L., Couturier, Y., Tousignant, M., Corbin, C., Delli-Colli, N. \& Raîche, M. (2013) Development of integrated care pathways: toward a care management system to meet the needs of frail and disabled community-dwelling older people. International Journal of Integrated Care, 13(2).

Dy, S. M., Garg, P., Nyberg, D., Dawson, P. B., Pronovost, P. J., Morlock, L., Rubin, H. \& Wu, A. W. (2005) Critical pathway effectiveness: Assessing the impact of patient, hospital care, and pathway characteristics using qualitative comparative analysis. Health Services Research, 40(2), pp. 499-516.

Eddy, D. M. (1984) Variations in physician practice: the role of uncertainty. Health Affairs, 3(2), pp. 74-89.

Edgren, L. \& Stenberg, G. (2006) The face of community care [In Swedish], Lund, Studentlitteratur.

Eisenhardt, K. (1989) Building theories from case study research. Academy of Management Review, 14(4), pp. 532-550.

Elg, M., Engström, J., Witell, L. \& Poksinska, B. (2012) Co-creation and learning in health-care service development. Journal of Service Management, 23(3), pp. 328-343.

Elg, M., Lindmark, J., Wiger, M. \& Wihlborg, E. (2016) Translation of guidelines: Case studies on the impact of methods for disease prevention Linköping: Linköping University Electronic Press.

Elg, M., Lindmark, J. And Hellström, A. (2011) Process orientation in healthcare services: The flow model as a way to follow the patient's journey through the healthcare system. 18th International Annual Euroma Conference. Cambridge, UK.

Elwyn, G., Quinlan, C., Mulley, A., Agoritsas, T., Vandvik, P. O. \& Guyatt, G. (2015) Trustworthy guidelines-excellent; customized care tools-even better. BMC Medicine, 13(199), pp. DOI 10.1186/s12916-015-0436-y.

Epstein, R. M. \& Street, R. L. (2011) The values and value of patient-centered care. Annals of Family Medicine, 9(2), pp. 100-103.

Essén, A. (2008) Balancing standardisation and customisation in the public elderly care setting. International Journal of Mass Customisation, 2(3-4), pp. 324-340. 
Fogliatto, F. S., Da Silveira, G. J. \& Borenstein, D. (2012) The mass customization decade: An updated review of the literature. International Journal of Production Economics, 138(1), pp. 14-25.

Freijser, L., Naccarella, L., Mckenzie, R. \& Krishnasamy, M. (2015) Cancer care coordination: Building a platform for the development of care coordinator roles and ongoing evaluation. Australian Journal of Primary Health, 21(2), pp. 157-163.

Fältholm, Y. \& Jansson, A. (2008) The implementation of process orientation at a Swedish hospital. The International Journal of Health Planning and Management, 23(3), pp. 219-233.

Galbraith, J. R. (1974) Organization design: An information processing view. Interfaces, 4(3), pp. 2836.

Gemmel, P., Vandaele, D. \& Tambeur, W. (2008) Hospital Process Orientation (HPO): The development of a measurement tool. Total Quality Management, 19(12), pp. 1207-1217.

Gittell, J. H., Fairfield, K. M., Bierbaum, B., Head, W., Jackson, R., Kelly, M., Laskin, R., Lipson, S., Siliski, J. \& Thornhill, T. (2000) Impact of relational coordination on quality of care, postoperative pain and functioning, and length of stay: a nine-hospital study of surgical patients. Medical care, 38(8), pp. 807-819.

Glouberman, S. \& Mintzberg, H. (2001) Managing the care of health and the cure of disease - Part I: Differentiation. Health care management review, 26(1), pp. 56-69.

Goodwin, N., Sonola, L., Thiel, V. \& Kodner, D. L. (2013) Co-ordinated care for people with complex chronic conditions. Key lessons and markers for success. London: The King's Fund.

Government Offices of Sweden (1982) The Swedish Health Care Act. In: MINISTRY OF HEALTH AND SOCIAL AFFAIRS (ed.). Stockholm: Statute book.

Greenfield, D., Eljiz, K. \& Butler-Henderson, K. (2018) It Takes Two to Tango: Customization and Standardization as Colluding Logics in Healthcare: Comment on"(Re) Making the Procrustean Bed Standardization and Customization as Competing Logics in Healthcare". International Journal of Health Policy and Management, 7(2), pp. 183.

Grimshaw, J., Thomas, R., Maclennan, G., Fraser, C., Ramsay, C., Vale, L., Whitty, P., Eccles, M., Matowe, L. \& Shirran, L. (2004) Effectiveness and efficiency of guideline dissemination and implementation strategies. Health Technology Assessment, 8(6), pp. 1-72.

Grol, R. (2001) Successes and failures in the implementation of evidence-based guidelines for clinical practice. Medical care, 39(8), pp. II-46-II-5.

Gröne, O. \& Garcia-Barbero, M. (2001) Integrated care. International Journal of Integrated Care, 1(2), pp. 1-10.

Grönroos, C. (1984) A service quality model and its marketing implications. European Journal of Marketing, 18(4), pp. 36-44.

Gwinner, K. P., Bitner, M. J., Brown, S. W. \& Kumar, A. (2005) Service customization through employee adaptiveness. Journal of Service Research, 8(2), pp. 131-148.

Haggerty, J. L., Reid, R. J., Freeman, G. K., Starfield, B. H., Adair, C. E. \& Mckendry, R. (2003) Continuity of care: A multidisciplinary review. BMJ: British Medical Journal, 327(7425), pp. $1219-1221$.

Han, P. K. J., Klein, W. M. P. \& Arora, N. K. (2011) Varieties of Uncertainty in Health Care: A Conceptual Taxonomy. Medical Decision Making, 31(6), pp. 828-838.

Harvey, J., Lefebvre, L. A. \& Lefebvre, E. (1997) Flexibility and technology in services: A conceptual model. International Journal of Operations \& Production Management, 17(1), pp. 29-45.

Hellström, A., Lifvergren, S. \& Quist, J. (2010) Process management in healthcare: Investigating why it's easier said than done. Journal of Manufacturing Technology Management, 21(4), pp. 499511.

Hoffer Gittell, J. (2002) Coordinating mechanisms in care provider groups: Relational coordination as a mediator and input uncertainty as a moderator of performance effects. Management Science, 48(11), pp. 1408-1426.

Holland, D. E. \& Harris, M. R. (2007) Discharge planning, transitional care, coordination of care, and continuity of care: clarifying concepts and terms from the hospital perspective. Home Health Care Services Quarterly, 26(4), pp. 3-19.

Institute of Medicine (2001) Crossing the Quality Chasm: A New Health System for the 21st Century, Washington, DC: National Academy Press.

Ishikawa, K. (1990) Introduction to Quality Control, Tokyo, 3A Corporation. 
Jansen, J. \& Corley, K. (2007) E-survey methodology. Handbook of research on electronic surveys and measurements. IGI Global.

Jensen, H. (2015) Implementation of Cancer Patient Pathways and the Association with More Timely Diagnosis and Earlier Detection of Cancer Among Incident Cancer Patients in Primary Care. $\mathrm{PhD}$ Dissertation, Aarhus University.

Jensen, H., Tørring, M. L., Olesen, F., Overgaard, J., Fenger-Grøn, M. \& Vedsted, P. (2015) Diagnostic intervals before and after implementation of cancer patient pathways-a GP survey and registry based comparison of three cohorts of cancer patients. BMC cancer, 15(1), pp. 308.

Killander, E., Modig, G. \& Nilsson, G. (1999) Believe in the patient: treatment of tumor-related pain [In Swedish], Lund, Studentlitteratur.

Knebel, E. \& Greiner, A. C. (2003) Health professions education: A bridge to quality, Washington(DC), National Academies Press.

Kohn, L. T., Corrigan, J. \& Donaldson, M. S. (2000) To err is human: building a safer health system, Washington (DC), National Academies Press.

Koontz, H. (1961) The management theory jungle. Academy of Management journal, 4(3), pp. 174-188.

Kovács, G. \& Spens, K. M. (2005) Abductive reasoning in logistics research. International Journal of Physical Distribution \& Logistics Management, 35(2), pp. 132-144.

Kvale, S. (1996) InterViews. An introduction to Qualitative Research Interviewing, Thousand Oaks, CA, SAGE Publications.

Lampel, J. \& Mintzberg, H. (1996) Customizing customization. Sloan management review, 38(1), pp. 21-30.

Larsen, M. B., Hansen, R. P., Hansen, D. G., Olesen, F. \& Vedsted, P. (2013) Secondary care intervals before and after the introduction of urgent referral guidelines for suspected cancer in Denmark: a comparative before-after study. BMC Health Services Research, 13(1), pp. 348.

Larsson, M. \& Bjuresäter, K. (2016) Contact nurses in cancer care. A study of present organisations in Region Uppsala-Örebro [in Swedish]. Uppsala.

Lawrence, P. R. \& Lorsch, J. W. (1967) Differentiation and integration in complex organizations. Administrative Science Quarterly, 12(1), pp. 1-47.

Levitt, T. (1976) The industrialization of service. Harvard Business Review, 54, pp. 63-74.

Lie, N.-E., Solvang, P. \& Hauken, M. (2018a) From Challenges to Resources: A Qualitative Study of Cancer Coordinators' Experiences of Barriers and Facilitators to Enacting Their SystemFocused Tasks. Cancer Nursing.

Lie, N.-E. K., Hauken, M. A. \& Solvang, P. K. (2018b) Providing Coordinated Cancer Care-a Qualitative Study of Norwegian Cancer Coordinators' Experiences of Their Role. Cancer nursing, 41(6), pp. 463-472.

Lillrank, P. (2002) The broom and nonroutine processes: A metaphor for understanding variability in organizations. Knowledge and process management, 9(3), pp. 143-148.

Lillrank, P. (2003) The quality of standard, routine and nonroutine processes. Organization Studies, 24(2), pp. 215-233.

Lillrank, P. \& Liukko, M. (2004) Standard, routine and non-routine processes in health care. International Journal of Health Care Quality Assurance, 17(1), pp. 39-46.

Lovelock, C. \& Gummesson, E. (2004) Whither services marketing? In search of a new paradigm and fresh perspectives. Journal of Service Research, 7(1), pp. 20-41.

Lusk, J. M. \& Fater, K. (2013) A Concept Analysis of Patient-Centered Care. Nursing Forum, 48(2), pp. 89-98.

Malone, T. W. (1988) What is coordination theory? Cambridge: Massachusetts Institute of Technology.

Malone, T. W. \& Crowston, K. (1994) The interdisciplinary study of coordination. ACM Computing Surveys (CSUR), 26(1), pp. 87-119.

Manage, (n.d.) (2019) In Oxford Dictionaries English. Retrieved from https://en.oxforddictionaries.com/english, 2019-04-20.

Mannion, R. \& Exworthy, M. (2017) (Re)Making the procrustean bed? Standardization and customization as competing logics in healthcare. International Journal of Health Policy and Management, 6(6), pp. 301-304.

Maxwell, R. J. (1992) Dimensions of quality revisited: From thought to action. Quality in health care, 1(3), pp. 171. 
Mcdonald, K. M., Sundaram, V., Bravata, D. M., Lewis, R., Lin, N., Kraft, S. A., Mckinnon, M., Paguntalan, H. \& Owens, D. K. (2007) Care coordination. In: SHOJANIA, K. G., MCDONALD, K. M., WACHTER, R. M. \& OWENS, D. K. (eds.) Closing the quality gap: a critical analysis of quality improvement strategies. Rockville, MD: Agency for Healthcare Research and Quality.

Meijboom, B., Vaessen, P., Heijden, K. V. D., Sambeeck, M. V. \& Gemmel, P. (2018) Customization and personalization in clinical pathways using a modular perspective. 25th International EurOMA Conference. Budapest, Hungary.

Mercuri, M. \& Gafni, A. (2011) Medical practice variations: what the literature tells us (or does not) about what are warranted and unwarranted variations. Journal of Evaluation in Clinical Practice, 17(4), pp. 671-677.

Merriam, S. B. (1998) Qualitative Research and Case Study Applications in Education, San Francisco, Jossey-Bass.

Miles, M. \& Huberman, A. (1994) Qualitative data analysis: An expanded sourcebook, Thousand Oaks, SAGE publications, Inc.

Min, L. C., Reuben, D. B., Maclean, C. H., Shekelle, P. G., Solomon, D. H., Higashi, T., Chang, J. T., Roth, C. P., Kamberg, C. J. \& Adams, J. (2005) Predictors of overall quality of care provided to vulnerable older people. Journal of the American Geriatrics Society, 53(10), pp. 1705-1711.

Mintzberg, H. (1980) Structure in 5's: A Synthesis of the Research on Organization Design. Management science, 26(3), pp. 322-341.

Mintzberg, H. (1989) The structuring of organizations. Readings in Strategic Management. Springer.

Mintzberg, H. \& Glouberman, S. (2001) Managing the care of health and the cure of disease-Part II: Integration. Health care management review, 26(1), pp. 70-84.

Mintzberg, H., Lampel, J., Quinn, J. \& Ghoshal, S. (2003) The strategy process: concepts, contexts, cases, Essex, Pearson education.

Minvielle, E., Waelli, M., Sicotte, C. \& Kimberly, J. R. (2014) Managing customization in health care: A framework derived from the services sector literature. Health Policy, 117(2), pp. 216-227.

Mittal, B. \& Lassar, W. M. (1996) The role of personalization in service encounters. Journal of retailing, 72(1), pp. 95-109.

Monterosso, L., Platt, V., Krishnasamy, M., Yates, P. \& Bulsara, C. (2016) The cancer nurse coordinator service in Western Australia: Perspectives of specialist cancer nurse coordinators. Australian Journal of Advanced Nursing, 34(2), pp. 16-26.

Nazareth, I., Jones, L., Irving, A., Aslett, H., Ramsay, A., Richardson, A., Tookman, A., Mason, C. \& King, M. (2008) Perceived concepts of continuity of care in people with colorectal and breast cancer-a qualitative case study analysis. European Journal of Cancer Care, 17(6), pp. 569-577.

NBHW (2006) Good quality of care - management system for quality and patient safety in health care [In Swedish]. Stockholm.

NBHW (2015a) Standardised cancer patient pathways. A basline report [In Swedish]. Stockholm.

NBHW (2015b) Standardised cancer patient pathways. Progress report 2015 [In Swedish]. Stockholm.

NBHW (2016) Standardised cancer patient pathways. Progress report 2016 [In Swedish]. Stockholm.

NBHW (2017) Standardised cancer patient pathways. Progress report 2017 [In Swedish]. Stockholm.

NBHW (2018) Standardised cancer patient pathways. Progress report 2018 [In Swedish]. Stockholm.

Nilsson, F. (2007) The complex health care - About complexity and complex processes in the health care sector [report in Swedish]. Region Skåne, The Development Centre.

Nolte, E. \& Mckee, C. M. (2008) Measuring the health of nations: Updating an earlier analysis. Health Affairs, 27(1), pp. 58-71.

Nutt, M. \& Hungerford, C. (2010) Nurse care coordinators: Definitions and scope of practice. Contemporary Nurse, 36(1-2), pp. 71-81.

Ouwens, M., Wollersheim, H., Hermens, R., Hulscher, M. \& Grol, R. (2005) Integrated care programmes for chronically ill patients: A review of systematic reviews. International journal for quality in health care, 17(2), pp. 141-146.

Palmberg, K. (2009) Exploring process management: Are there any widespread models and definitions? The TQM Journal, 21(2), pp. 203-215.

Palmer, K., Marengoni, A., Forjaz, M. J., Jureviciene, E., Laatikainen, T., Mammarella, F., Muth, C., Navickas, R., Prados-Torres, A. \& Rijken, M. (2018) Multimorbidity care model: 
Recommendations from the consensus meeting of the Joint Action on Chronic Diseases and Promoting Healthy Ageing across the Life Cycle (JA-CHRODIS). Health Policy, 122(1), pp. 411.

Panella, M., Van Zelm, R., Sermeus, W. \& Vanhaecht, K. (2012) Care pathways for the organization of patients' care. Bulletin: Economics, Organisation and Informatics in Healthcare, 28(2), pp. 111122.

Patton, M. Q. (2002) Qualitative research and evaluation methods, Thousand Oaks, CA, Sage Publications.

Pearson, S. D., Goulart-Fisher, D. \& Lee, T. H. (1995) Critical pathways as a strategy for improving care: Problems and potential. Annals of Internal Medicine, 123(12), pp. 941-948.

Piller, F. T. (2007) Observations on the present and future of mass customization. International Journal of Flexible Manufacturing Systems, 19(4), pp. 630-636.

Pine, B. J. (1993) Mass customizing products and services. Planning review, 21(4), pp. 6-55.

Plsek, P. E. \& Greenhalgh, T. (2001) Complexity science: The challenge of complexity in health care. BMJ: British Medical Journal, 323(7313), pp. 625.

Poksinska, B. (2007) Does standardisation have a negative impact on working conditions? Human Factors and Ergonomics in Manufacturing, 17(4), pp. 1-12.

Poksinska, B. (2018) Improving quality of care for patients with complex needs. 21th QMOD conference on Quality and Service Sciences ICQSS. Cardiff, UK.

Poksinska, B., Fialkowska, M. \& Engström, J. (2014) Does Lean Healthcare lead to improvement of patient-perceived quality of care? 17th QMOD conference on Quality and Service Sciences ICQSS 2014. Prague, Czech Republic.

Porter, M. E. (2008) Value-based health care delivery. Annals of Surgery, 248(4), pp. 503-509.

Potter, S., Govindarajulu, S., Shere, M., Braddon, F., Curran, G., Greenwood, R., Sahu, A. K. \& Cawthorn, S. J. (2007) Referral patterns, cancer diagnoses, and waiting times after introduction of two week wait rule for breast cancer: prospective cohort study. BMJ: British Medical Journal, 335(7614), pp. 288.

Probst, H. B., Hussain, Z. B. \& Andersen, O. (2012) Cancer patient pathways in Denmark as a joint effort between bureaucrats, health professionals and politicians - a national Danish project. Health Policy, 105(1), pp. 65-70.

RCC (2017) National function description of coordinators for standardised cancer care pathways [In Swedish]. Stockholm.

Regional Cancer Centre in Coorporation. (2019) Number of patients in CCPs [In Swedish] [Online]. Available at: https://www.cancercentrum.se/samverkan/vara-uppdrag/statistik/svfstatistik/resultat-och-statistik/ [Accessed 2019-04-14].

Regional Cancer Centre in South of Sweden. (2019) Diagnostic centre [in Swedish] [Online]. Available: https://www.cancercentrum.se/syd/vara-uppdrag/prevention-och-tidigupptackt/prevention/diagnostiskt-centrum/ [Accessed 2019-03-19].

RJH (2018) Action plan for the region Jämtland Härjedalen 2018 [In Swedish]. Online.

Rose, N. (2013) Personalized medicine: Promises, problems and perils of a new paradigm for healthcare. Procedia-Social and Behavioral Sciences, 77, pp. 341-352.

Rosell, L., Alexandersson, N., Hagberg, O. \& Nilbert, M. (2018) Benefits, barriers and opinions on multidisciplinary team meetings: a survey in Swedish cancer care. BMC Health Services Research, 18(1), pp. 249.

RÖ (2014) Cancer diagnostics in a university hospital - a pilot study in cooperation with primary care [In Swedish]. Linköping.

RÖ (2015) Development of adapted care pathways - identification of target population [In Swedish]. Linköping.

RÖ (2016) Implementation of standardised care pathways. Implementaion report 2016 [In Swedish]. Linköping.

RÖ (2018) Serious unspecific symptoms and experiences from Region of Östergötland [In Swedish]. In conference: Utvecklingskraft cancer - Huskvarna, Sweden, date 2018-05-17.

Sackett, D. L. \& Rosenberg, W. M. C. (1995) On the need for evidence-based medicine. Journal of Public Health, 17(3), pp. 330-334.

SALAR (2012) Contact nurse in cancer care - report [in Swedish]. Stockholm. 
SALAR (2015) Swedish health care in international comparison. Stockholm.

Sanson-Fisher, R., Girgis, A., Boyes, A., Bonevski, B., Burton, L., Cook, P. \& Group, S. C. R. (2000) The unmet supportive care needs of patients with cancer. Cancer, 88(1), pp. 226-237.

Schmidt, I., Thor, J., Davidson, T., Nilsson, F. \& Carlsson, C. (2018) The national program on standardized cancer care pathways in Sweden: Observations and findings half way through. Health Policy, 122(9), pp. 945-948.

Schoen, C., Osborn, R., How, S. K., Doty, M. M. \& Peugh, J. (2009) In chronic condition: experiences of patients with complex health care needs, in eight countries, 2008. Health Affairs, 28(1), pp. w1-w16.

Schoen, C., Osborn, R., Squires, D., Doty, M., Pierson, R. \& Applebaum, S. (2011) New 2011 survey of patients with complex care needs in eleven countries finds that care is often poorly coordinated. Health Affairs, 30(12), pp. 2437-2448.

Scott, W. R. (2015) Organizations and organizing: Rational, natural and open systems perspectives, London, Routledge.

Sermeus, W., De Bleser, L., Depreitere, R., De Waele, K., Vanhaecht, K. \& Vlayen, J. (2005) An introduction to clinical pathways. in Devriese $S$, Lambert ML, Eyssen M, Van De Sande $S$, Poelmans J, Van Brabandt $H$ et al., editors. The use of clinical pathways and guidelines to determine physicians' hospital fees prospectively: easier said than done. Brussels.

Shaw, T., York, S., White, K., Mcgregor, D., Rankin, N., Hawkey, A., Aranda, S., Rushton, S. \& Currow, D. (2018) Defining success factors to describe coordinated care in cancer. Translational Behavioral Medicine, 8(3), pp. 357-365.

Shojania, K. G. \& Grimshaw, J. M. (2005) Evidence-based quality improvement: The state of the science. Health Affairs, 24(1), pp. 138-150.

Simon, S. R., Chan, K. A., Soumerai, S. B., Wagner, A. K., Andrade, S. E., Feldstein, A. C., Lafata, J. E., Davis, R. L. \& Gurwitz, J. H. (2005) Potentially inappropriate medication use by elderly persons in US Health Maintenance Organizations, 2000-2001. Journal of the American Geriatrics Society, 53(2), pp. 227-232.

Smeds, M. (2016) Implementation of standardized patient pathways: A shortcut into cancer care [In Swedish]. Master thesis. Linköping University.

Smith, S., Nicol, K., Devereux, J. \& Cornbleet, M. (1999) Encounters with doctors: Quantity and quality. Palliative Medicine, 13(3), pp. 217-223.

SOU (2009) A national cancer strategy for the future. Stockholm.

Sousa, R. \& Voss, C. A. (2002) Quality management re-visited: a reflective review and agenda for future research. Journal of Operations Management, 20(1), pp. 91-109.

Stabell, C. B. \& Fjeldstad, Ø. D. (1998) Configuring value for competitive advantage: On chains, shops, and networks. Strategic management journal, 19, pp. 413-437.

Starfield, B., Lemke, K. W., Bernhardt, T., Foldes, S. S., Forrest, C. B. \& Weiner, J. P. (2003) Comorbidity: implications for the importance of primary care in 'case'management. The Annals of Family Medicine, 1(1), pp. 8-14.

Stein, T., Frankel, R. M. \& Krupat, E. (2005) Enhancing clinician communication skills in a large healthcare organization: a longitudinal case study. Patient education and counseling, 58(1), pp. 4-12.

Sundström, G. (2018) Future University Hospital - Decision about new Karolinska Solna - Interim report 2018-02-23. Stockholm University.

Surprenant, C. F. \& Solomon, M. R. (1987) Predictability and personalization in the service encounter. Journal of Marketing, 51(2), pp. 86-96.

The Swedish Cancer Society \& NBHW (2018) Cancer in numbers 2018. Stockholm.

The Swedish Government Inquiries (2001) Prioritisation in health care. 2001:8 ed. Stockholm.

Thomas-Henkel, C., Hendricks, T. \& Church, K. (2015) Opportunities to improve models of care for people with complex needs: Literature review. The Robert Wood Johnson Foundation and Center for Health Care Strategies.

Timmermans, S. \& Berg, M. (2003) The Gold Standard: The Challenge of Evidence-based Medicine and Standardization in Health Care, Temple University Press.

Tinghög, G., Andersson, D., Tinghög, P. \& Lyttkens, C. H. (2014) Horizontal inequality in rationing by waiting lists. International Journal of Health Services, 44(1), pp. 169-184. 
Wagstaff, A. \& Van Doorslaer, E. (2000) Equity in health care finance and delivery. Handbook of Health Economics, 1(B), pp. 1803-1862.

Walsh, J., Young, J., Harrison, J., Butow, P., Solomon, M., Masya, L. \& White, K. (2011) What is important in cancer care coordination? A qualitative investigation. European Journal of Cancer Care, 20(2), pp. 220-227.

Vanhaecht, K. (2007) The impact of clinical pathways on the organisation of care processes. $\mathrm{PhD}$, Katholieke Universiteit Leuven.

Vanhaecht, K., Bollmann, M., Bower, K., Gallagher, C., Gardini, A., Guezo, J., Jansen, U., Massoud, R., Moody, K. \& Sermeus, W. (2006) Prevalence and use of clinical pathways in 23 countries - An international survey by the European Pathway Association. Journal of Integrated Care Pathways, 10(1), pp. 28-34.

Vanhaecht, K., De Witte, K. \& Sermeus, W. (2007) The Care Process Organisation Triangle: A framework to better understand clinical pathways. Journal of Care Pathways, 11(2), pp. 54-61.

Vanhaecht, K., Panella, M., Van Zelm, R. \& Sermeus, W. (2010) An overview on the history and concept of care pathways as complex interventions. International Journal of Care Pathways, 14(3), pp. 117-123.

Varley, A., Warren, F. C., Richards, S. H., Calitri, R., Chaplin, K., Fletcher, E., Holt, T. A., Lattimer, V., Murdoch, J., Richards, D. A. \& Campbell, J. (2016) The effect of nurses' preparedness and nurse practitioner status on triage call management in primary care: A secondary analysis of cross-sectional data from the ESTEEM trial. International Journal of Nursing Studies, 58, pp. $12-20$.

Wennberg, J. E. (2002) Unwarranted variations in healthcare delivery: implications for academic medical centres. BMJ: British Medical Journal, 325(7370), pp. 961.

Whelan, T. J., Mohide, E. A., Willan, A. R., Arnold, A., Tew, M., Sellick, S., Gafni, A. \& Levine, M. N. (1997) The supportive care needs of newly diagnosed cancer patients attending a regional cancer center. Cancer: Interdisciplinary International Journal of the American Cancer Society, 80(8), pp. 1518-1524.

Whellan, D. J., Gaulden, L., Gattis, W. A., Granger, B., Russell, S. D., Blazing, M. A., Cuffe, M. S. \& O'connor, C. M. (2001) The benefit of implementing a heart failure disease management program. Archives of Internal Medicine, 161(18), pp. 2223-2228.

WHO (2006) Quality of care: a process for making strategic choices in health systems. Geneva, Switzerland: World Health Organization.

Wiger, M. (2018) Logistics Management Operationalised in a Health Care Context - Understanding Care Chain Effectiveness through Logistics Management. Doctoral, Linköping University.

Wilkens, J., Thulesius, H., Schmidt, I. \& Carlsson, C. (2016) The 2015 National Cancer Program in Sweden: Introducing standardized care pathways in a decentralized system. Health Policy, 120(12), pp. 1378-1382.

Voss, C. A. \& Hsuan, J. (2009) Service architecture and modularity. Decision Sciences, 40(3), pp. 541569.

Yin, R. K. (2009) Case Study Research: Design and Methods, Sage Publications, Inc.

Zander, K. (2002) Integrated Care Pathways: Eleven International Trends. Journal of Integrated Care Pathways, 6(3), pp. 101-107.

Øvretveit, J. \& Gustafson, D. (2002) Evaluation of quality improvement programmes. BMJ Quality \& Safety, 11(3), pp. 270-275. 


\section{Papers}

The papers associated with this thesis have been removed for copyright reasons. For more details about these see:

http://urn.kb.se/resolve?urn=urn:nbn:se:liu:diva-156836 


\section{FACULTY OF SCIENCE AND ENGINEERING}

Linköping Studies in Science and Technology, Licentiate Thesis No. 1839, 2019 Department of Logistics and Quality Management

Linköping University

SE-581 83 Linköping, Sweden

wwW.liu.se 